\title{
Territorio y materialidad en el Bajo Segura durante el Bronce Final inicial: nuevos datos del asentamiento de Cobatillas la Vieja (Santomera, Murcia)
}

\author{
Territory and materiality in the lower valley of the \\ Segura River during the early Late Bronze Age: \\ new data from the settlement of Cobatillas la \\ Vieja (Santomera, Murcia)
}

\author{
BENJAMín CUTILLAS VICTORIA \\ Universidad de Murcia \\ Dpto. de Prehistoria, Arqueología, Historia Antigua, \\ Historia Medieval y CCTT. Historiográficas \\ benjamin.cutillas@um.es \\ https://orcid.org/0000-0002-6358-4176
}

\author{
JUAN FRANCISCO LÓPEZ ORTIGOSA \\ Arqueólogo Profesional \\ juanfrancisco.lopezortigosa@gmail.com \\ https://orcid.org/0000-0001-9276-8858
}

\section{Resumen}

El Sureste de la península ibérica experimentó durante el Bronce Final significativos procesos de reordenación poblacional visibles en la configuración espacial de sus asentamientos y en el nuevo paisaje político-territorial de la región. En el caso de la vega baja del Segura, el abandono de parte de los asentamientos postargáricos propició una orientación del poblamiento hacia nuevas posiciones en altura, bien interconectadas y estrechamente ligadas con las capacidades productivas de sus entornos. Paradigma de tales procesos es el asentamiento de Cobatillas la Vieja, inserto en un paisaje de amplia biodiversidad y relaciones territoriales arraigadas en épocas previas que facilitaron su reocupación en el nuevo escenario sociopolítico y económico de la zona. El análisis de tales circunstancias desde el prisma de la arqueología del paisaje, en conjunción con el estudio de la territorialidad e identidad de su materialidad, constituye el objetivo de este trabajo. Como resultado se pone de manifiesto la importancia de este enclave y su contextualización con el resto de centros cercanos con el fin de delimitar las problemáticas particulares que se dieron en las primeras etapas del Bronce Final en el Bajo Segura.

Palabras clave: Bronce Final, Sureste ibérico, paisajes de producción, territorio, estratigrafía, visibilidad, registro vascular

\section{Summary}

The population dynamics during Late Bronze Age in Southeast of the Iberian Peninsula caused a reorganization of its settlements and the beginning of a new political-territorial landscape of the region. In the lower Segura valley, the abandonment of part of the post-argaric occupations led to an orientation of the communities towards new positions in height, interconnected and linked with the productive capacities of their environments. The site of Cobatillas la Vieja is an appropriate case study for the review of this new model from its location in a landscape of wide territorial relations and biodiversity rooted in previous chronologies that facilitated its reoccupation in the new socio-political and economic scenario of the area. The purpose of this work is analyze these factors from the view of landscape archeology, in conjunction with the study of the territoriality and the identity of its materiality. The results introduce the importance of this settlement and its contextualization with the nearby centers in order to approach the particular problems that occurred in the early stages of the Late Bronze Age in the lower Segura river.

Key words: Late Bronze Age, southeastern Iberia, productive landscapes, territory, stratigraphy, visibility, ceramics 


\section{Introducción ${ }^{1}$}

La transición entre el período postargárico del Bronce Tardío y el Bronce Final estuvo marcada por una serie de importantes cambios estructurales que provocaron la profunda modificación del ambiente cultural del Sureste peninsular (Molina, 1978: 206; Ros, I989: 48). En los siglos anteriores a la transición del II al I milenio a. C., la emergencia de nuevas dinámicas de reestructuración territorial modificó el paisaje hasta entonces conocido, a la par que se introdujeron novedades en las materialidades que afectaron a los diferentes ámbitos de la cotidianeidad. Tales procesos se desarrollaron de forma progresiva y jugaron un papel significativo en la configuración de las comunidades de esta etapa, lo que acabó por confluir hacia una identidad que se ha planteado en algunos aspectos como culturalmente homogénea y en constante conexión con las dinámicas mayores que afectaban al resto de la península ibérica y al Mediterráneo Occidental (Molina, I978). No obstante, esta identidad en líneas generales común no implicó la ausencia de diferencias regionales o territoriales; estas existieron de forma constante a lo largo del período y dieron lugar a entidades culturales diferenciadas pese a localizarse en espacios compartidos e interconectados como el Bajo Segura.

Inmerso en esta coyuntura, el complejo poblacional de Cobatillas la Vieja se define como uno de los yacimientos clave para entender la dinámica poblacional prehistórica en las vegas media y baja del río Segura. Con una secuencia ocupacional discontinua que se prolonga desde el período argárico hasta el Ibérico Final, este asentamiento humano no se mantuvo estático durante su desarrollo, sino que sus

1 Esta investigación se ha realizado en el marco de las tareas comprendidas en el Proyecto Carthago Nova desde su entorno litoral. Paleotopografía y evolución medioambiental del sector central del Sureste Ibérico. Dinámica poblacional y productiva (HAR20I785726-C2-I-P) concedido por el MINECO. Este trabajo no hubiera sido posible sin los comentarios e indicaciones realizados por la doctora Milagros Ros Sala, quien ha enriquecido esta tarea aportando una mayor perspectiva sobre las problemáticas de este horizonte cultural. Igualmente queremos agradecer el trato recibido en el Museo Arqueológico de Murcia tanto por su director, Luis E. de Miquel, así como por todo el personal de la institución y sus fondos. áreas residenciales fueron trasladándose entre las diferentes elevaciones del actualmente denominado como Monte de las Brujas o de las Flechas (Santomera, Murcia). Esta micromovilidad juega un papel clave en la configuración del registro arqueológico, con sectores diferenciados, zonas reocupadas y períodos de hiatos que dificultan la interpretación de su secuencia cronoestratigráfica. Además, diferentes frentes de cantera contemporáneos han pulverizado uno de los cerros del conjunto por completo (figura I), así como parte del que alberga los hábitats del Bronce Final e Ibérico (Medina, I999: I29 y I42), afectando con ello a una parte de su conocimiento más exhaustivo

A pesar de esta coyuntura, el valor del yacimiento y su óptima localización no pasaron desapercibidos desde su descubrimiento en 1972 por M.J. Aragoneses, entonces director del Museo de Murcia. En diciembre de 1976 y abril de 1977 dos excavaciones de urgencia se iniciaron en el yacimiento, una centrada en el sector argárico del mismo dirigida por la doctora Muñoz Amilibia y otra sobre el sector ibérico dirigida por el doctor Lillo (figura I). En esta última se alcanzaron niveles y estructuras del Bronce Final inicial de los que únicamente fueron publicados los datos estratigráficos procedentes del corte $\tilde{\mathrm{N}}$ (Lillo, I976-I978; Lillo, I98I) y una revisión posterior de las vajillas cerámicas identificadas en los niveles preibéricos de dicha estratigrafia (Ros, 1985). Pero estas primeras intervenciones no tuvieron continuidad, al igual que las labores de investigación en cualquiera de sus fases, quedando gran parte del material inédito y pendiente un análisis exhaustivo de su singular localización medioambiental y de las relaciones sociopolíticas y económicas derivadas de su papel territorial en el contexto del Bajo Segura.

La contribución que aquí se presenta realiza precisamente un nuevo análisis de la secuencia del Bronce Final del yacimiento y su contextualización en el paisaje productivo, económico y político del momento. Su conjunción con la movilidad espacial de la propia comunidad que lo habitó y una nueva lectura del registro correspondiente al período del Bronce Final inicial, permiten avanzar novedades en cuanto a la identidad territorial de la zona y ajustar una serie de materialidades compartidas con otros núcleos del Sureste ibérico. La comprensión de un núcleo de estas características, en una posición geoestratégica de 

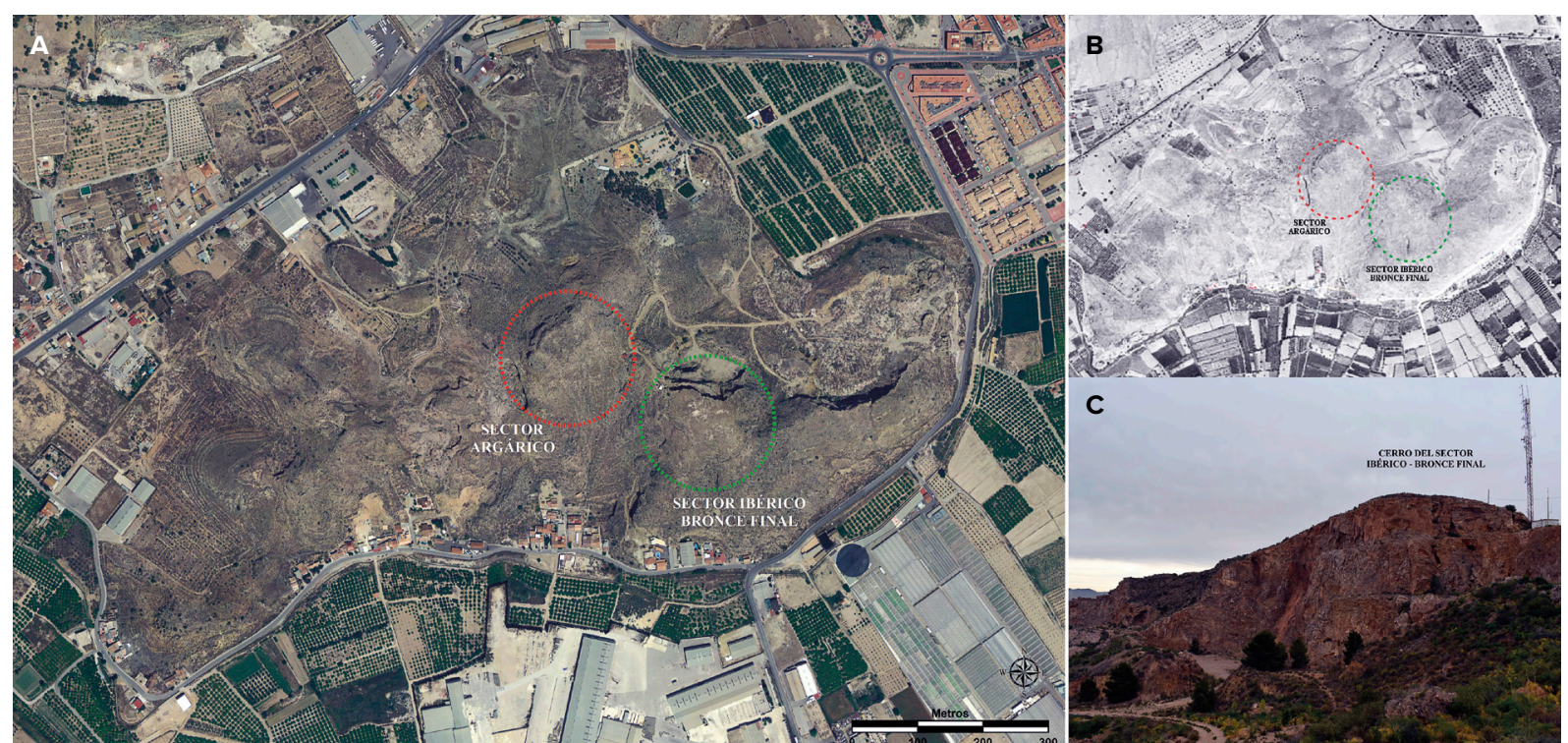

Figura 1. Fases de ocupación y entorno del yacimiento arqueológico. A. Situación del relieve de Cobatillas la Vieja con los dos sectores de hábitat destacados sobre una imagen aérea actual (PNOA-IGN). B. Fotograma del vuelo americano de 1956 del relieve sin las modificaciones producidas por las canteras (editada a partir de la Fototeca del IGN). C. Estado actual del sector ibérico con el cortado producido por la acción antrópica. (Imagen: archivo de los autores)

Figure 1. Phases of occupation and environment of the archaeological site. A. Situation of Cobatillas la Vieja with the two areas of settlements highlighted on a current aerial image (PNOA-Spanish National Geographic Institute). B. Photography of the 1956 American flight of the relief without the modifications produced by the quarries (edited from the National Geographic Institute archive). C. Current situation of the Iberian hill with the alterations produced by anthropic action. (Photography: authors)

control y proyección territorial respecto a la principal vía de comunicación y contacto del Sureste ibérico (figura 2), se presentaba como una tarea necesaria. Los nuevos datos que han surgido en los últimos años respecto al Bajo Segura y la zona de confluencia con el tramo medio del mismo río, con una serie de yacimientos poco conocidos pero cuya localización permite plantear su funcionalidad como centros de control territorial, denotan la existencia de un patrón poblacional complejo y dinámico. Para todas estas cuestiones, Cobatillas la Vieja juega un papel fundamental en las dinámicas generales que se dan en el Bajo Segura, lo que justifica esta nueva revisión sobre el yacimiento cuatro décadas después de las intervenciones sobre las que ahora se ha decidido volver.

\section{Territorios y dinámicas poblacionales de la Edad del Bronce en la Vega Baja del Segura}

El análisis transversal mediante la arqueología del paisaje aplicado a las estructuras sociales que se desarrollaron a lo largo de la Edad del Bronce en el tramo bajo del río Segura, muestra la importancia que los sistemas intermedios de la cuenca jugaron en las dinámicas urbanísticas y patrones de ocupación de estas comunidades. Localizados entre la llanura aluvial y las cadenas montañosas, estas posiciones se convirtieron en puntos de concentración poblacional sobre los que se vertebraron los territorios a partir del cumplimiento de un doble objetivo: ocupar lugares elevados en los que contar con una posición geoestratégica, defensiva y de relevancia visual respecto a su entorno inmediato, sin alejarse de las tierras fértiles de la cuenca y de las unidades rurales de menor tamaño que debían componer una parte esencial de sus tejidos productivos. Así, se aprovecharon emplazamientos con una gran capacidad de control visual y que, recíprocamente, también fueran cognoscibles desde el valle. En este sentido no se debe olvidar que la dimensión espacial adquiere funciones de identidad para los grupos humanos (Hernando, 2002: 8I-82), y una parte muy importante de este complejo proceso es que la percepción del territorio constituye un parámetro de construcción cultural de la realidad (Comino, 20I6: 17).

Bajo estas premisas se enmarcan en la zona los asentamientos correspondientes al período argárico: 


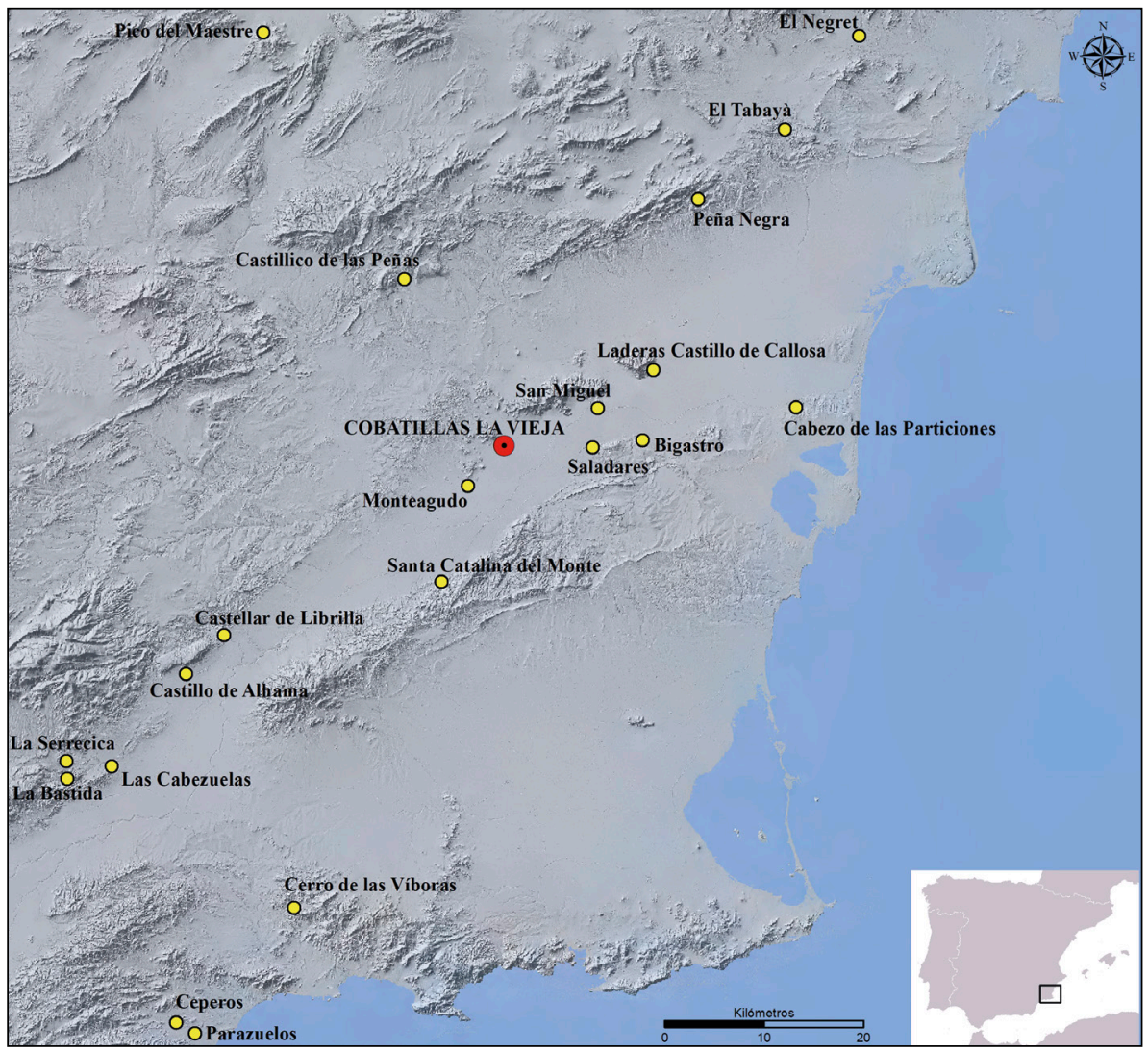

Figura 2. Localización del yacimiento arqueológico de Cobatillas la Vieja con los yacimientos principales citados en el texto. (Elaboración propia a partir del Modelo Digital del Terreno del IGN)

Figure 2. Location of the settlement of Cobatillas la Vieja with the aim sites mentioned in the text. (Design: authors and Digital Terrain Model from Spanish National Geographic Institute)

Santa Catalina, Puntarrón Chico y Cerro del Castillo de Monteagudo hacia el tramo medio del Segura; El Castellar de Zeneta, Cañadas de San Pedro, Cabezo Negro en la sierra de la Cresta del Gallo; o los yacimientos de San Antón y las Laderas del Castillo de Callosa en la zona oriolana. Los datos actuales sugieren, por tanto, un modelo que no difiere del planteado para los poblados argáricos de la cuenca del Guadalentín (Lull, I983), si bien es cierto que hay que apuntar el grado de conocimiento todavía deficitario en torno a las unidades rurales que conformarían los tejidos productivos de estas comunidades del Bronce Pleno.

Producto de este ámbito cultural, el hábitat argárico de Cobatillas la Vieja se localiza sobre el cerro de mayor altura del complejo, caracterizado por una fuerte pendiente que finaliza de forma abrupta en unas paredes escarpadas que sirven como destacadas defensas naturales (figura 3 ). La propia morfología del cerro obligó a sus habitantes a realizar una importante labor de adecuación de su superficie, ejecutando una serie de terrazas en las que las plantas de las casas se adaptaron a las condiciones topográficas del terreno (Medina, 1999: 127). Esta disposición escalonada en ladera coincide con la identificada en otros asentamientos cercanos, como el Puntarrón Chico o Santa Catalina del Monte (Ayala, 1982: 66), al igual que los patrones de construcción, con casas de tamaño considerable y planta poligonal, con un primer alzado de piedra y techumbres a base de carrizo y barro (Lull, I983: 335; Medina, 1999: 127). Entre las construcciones exhumadas se identificó en su interior un taller de sílex con una actividad muy intensa ligada a la producción de útiles relacionados con la agricultura, como dientes de hoz, cuchillos o percutores (Ayala, I98r: 156). El sílex tiene su origen al norte del yacimiento, en los afloramientos de la cercana Rambla Salada (Medina, I999: I28) donde se han localizado varios talleres líticos al aire libre (Jiménez et alii, 2005; Jiménez et alii, 2006). 


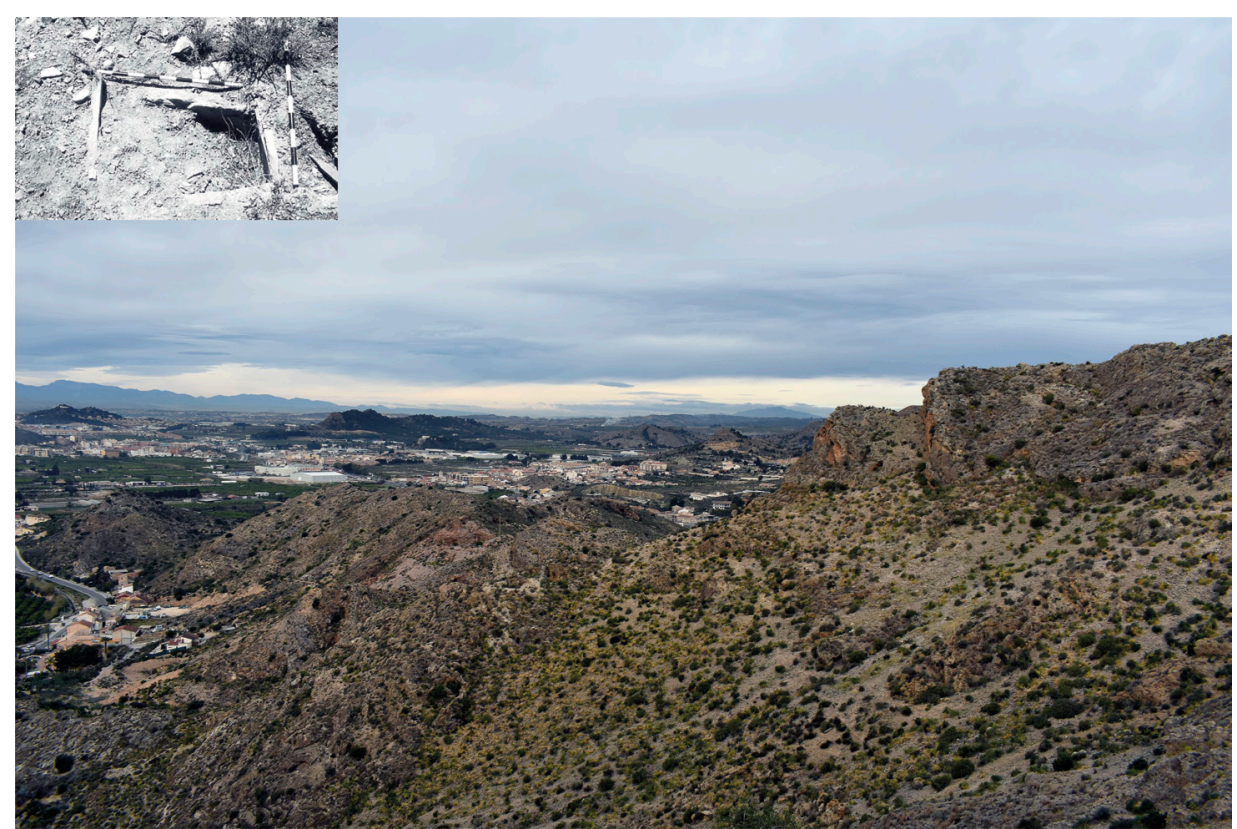

Figura 3. Vista de la ladera sur-sureste del sector argárico Cobatillas la Vieja en la que se aprecia la clara pendiente de la misma y posición respecto a la cuenca media y baja del Segura. (Imagen: archivo de los autores). Detalle: Cista de enterramiento argárico expoliada (Medina, 1990: 130)

Figure 3. View of the south-southeast hillside of Argaric sector at Cobatillas la Vieja; the slope and position respect to the middle and lower basin of the Segura River can be seen. (Photography:

authors). Detail: Looted argaric burial cist (Medina, 1990: 130)

La ejecución de estas actividades en el interior del poblado manifiesta la participación de la comunidad en tareas agrícolas y sus actividades derivadas; una correlación que se mantuvo activa en las fases siguientes como atestigua el hallazgo regular de estos elementos de sílex, junto a molinos barquiformes y de mano.

El final de la ocupación del hábitat argárico parece originarse en el marco de los procesos de reestructuración territorial que se suceden durante la etapa postargárica del Bronce Tardío y que afectan de manera desigual a los yacimientos del Bajo Segura. No obstante, los datos actuales no permiten establecer con claridad si este se produjo de forma drástica o respondió a un debilitamiento progresivo del hábitat argárico, como sucede en otros asentamientos del mismo marco cultural como Cabezo Redondo (Hernández et alii, 2or6), Fuente Álamo (Arteaga y Schubart, 1980), Cerro de la Encina (Arribas et alii, 1974) o Cuesta del Negro (Molina y Pareja, 1975); tampoco si este posible cambio tuvo como escenario el propio cerro de Cobatillas argárico, es decir, si se produjo ya en el propio lugar del asentamiento, o si, por el contrario, supuso la elección intencionada de un nuevo escenario geográfico. En cualquier caso, este período de aparente despoblación finalizará con el inicio del Bronce Final del Sureste ibérico y el nuevo proceso de reordenación territorial al que va asociado (Jover et alii, 20r6). A partir del siglo XıI a. C. aparecen algunos hábitats de nueva planta como Botx-Grupintex (Trelis et alii, 2004), mientras que se produce la reocupación de antiguos espacios habitados en períodos anteriores, como es el caso de Cobatillas. No obstante, esta nueva reocupación no se realiza sobre el cerro ocupado en época argárica, sino que el poblamiento se desplaza por completo hacia el cerro anexo.

Este segundo cerro o cerro del «sector ibérico», cuenta con una cima amesetada sobre unas paredes verticales que dificultan su acceso, únicamente posible por uno de los collados al oeste de la posición. Precisamente las intervenciones en la parte alta de la cima de este cono, los cortes $\mathrm{My} \tilde{\mathrm{N}}$, permitieron alcanzar los niveles y estructuras correspondientes al menos a una primera etapa del Bronce Final, adscripción confirmada gracias a la datación radiocarbónica obtenida de una muestra de carbón (Lillo, 1976-1978: 396). Pese a ser una muestra de vida larga extraída del hogar 
del nivel Ñ.VI, sus resultados proporcionaron una fecha aproximada de ro60 \pm 50 a. C. (Lillo Carpio 198r; Ros Sala 1985) cuya calibración posterior ha permitido ajustar su resultado en torno al I298 CAL BC (Castro Martínez et alii, 1996: 174-175). Los intervalos calculados para esta datación, que abarcan del I400 al II95, señalan cronológicamente esta etapa entre el Bronce Tardío y los primeros compases del Bronce Final, en consonancia con los datos que están ofreciendo otros yacimientos del Sureste ibérico para este momento de transición, tanto en su extremo meridional como en la parte septentrional (Castro et alii, 1996; Jover et alii, 2016).

La ocupación de Cobatillas la Vieja en este período se circunscribe, al igual que sucedía en el sector argárico, a un momento muy determinado que no tuvo continuidad en el tiempo al menos en la ladera intervenida por Lillo. Pese a lo limitado de los datos, no se han identificado fases constructivas ni remodelaciones posteriores que apunten hacia otros momentos dentro del final del II milenio a. C.; una perspectiva que también se desprende de la homogeneidad de los tipos y manufacturas de la vajilla cerámica (Ros, 1985). Por tanto, el inicio de la ocupación correspondiente al Bronce Final inicial coincide con un proceso de reordenación poblacional cuyas repercusiones son importantes para los territorios y paisajes del Sureste ibérico. En el curso bajo del Segura tiene lugar, por un lado, la reocupación de ciertos núcleos, tanto de nueva planta como ocupados en fases más antiguas; mientras que, por otro, existen una serie de núcleos continuistas que coinciden con aquellos asentamientos de mayor tradición, como ocurre en los casos de Santa Catalina del Monte, Monteagudo o El Tabayà. No obstante, también otros asentamientos como San Miguel (Soriano Sánchez, 1984; Diz, 1993), Cabezo de las Particiones (Soriano Sánchez, I985; Martínez Monleón, 2015) y Loma de Bigastro (Soriano Sánchez, 1985) muestran la pervivencia de unas estrategias iniciadas en períodos anteriores y que también se reproducen en los asentamientos fundados o reocupados durante esta fase. Entre estos últimos casos se encuadra Cobatillas la Vieja, con una ocupación de nueva planta, pero dentro del mismo complejo geográfico, que viene a cerrar el hiato poblacional coincidente con el período postargárico. La búsqueda de nuevas posiciones cristaliza también en el ámbito de la explotación agrícola, como es el caso del conjunto de ocupaciones detectadas para el Bronce Final inicial del Botx-Grupintex y su entorno inmediato (Trelis et alii, 2004).

En el caso que aquí nos ocupa, el traslado del hábitat que se ha constatado en Cobatillas la Vieja desde el sector argárico al ibérico persigue, entre otros fines más difíciles de percibir, una mejora del radio de visibilidad y control de los pasos circundantes desde el yacimiento. Desde el nuevo emplazamiento se cuenta, primero, con un mayor control del acceso a la Rambla Salada y de los pasos ganaderos que transitaran por esta ruta, a pesar de que parte de la propia rambla queda oculta tras el Collado Bermejo, una de las principales referencias geográficas y visuales de la zona por su gran altura; $y$, segundo, se amplía el control visual del territorio inmediato, mejorando significativamente su proyección hacia la cuenca del Segura, especialmente hacia su desembocadura (figuras 4 y 5). Ahora se perciben claramente otros asentamientos de la sierra de Orihuela y su entorno, como las Laderas de San Miguel o el yacimiento de La Loma de Bigastro; incluso, con una cronología más reciente, el asentamiento de Los Saladares. Todo ello manteniendo, al igual que en época argárica, el control visual de las rutas venidas desde el oeste y el puerto de Zacacho, a las que ahora se suman los pasos serranos hacia el sur y el sureste por donde discurren las rutas comerciales que conectan por tierra con los entornos litorales y por donde podrían llegar algunos de los recursos mineros cuyo uso se encuentra atestiguado en esta fase del poblado, como la galena argentífera.

La nueva posición, pese a ser el resultado de una movilidad reducida, mantiene la comunicación visual con los principales yacimientos contemporáneos próximos con fases del Bronce Final inicial. Es el caso de Monteagudo, el núcleo más cercano y con una entidad que, pese a los escasos datos con los que se cuenta por el momento (Medina, 2002), jugaría un papel principal en la articulación de este territorio por su posición y su representatividad en la cuenca. Más alejado se observa Santa Catalina del Monte que, aunque queda fuera del radio de visibilidad marcado sobre 


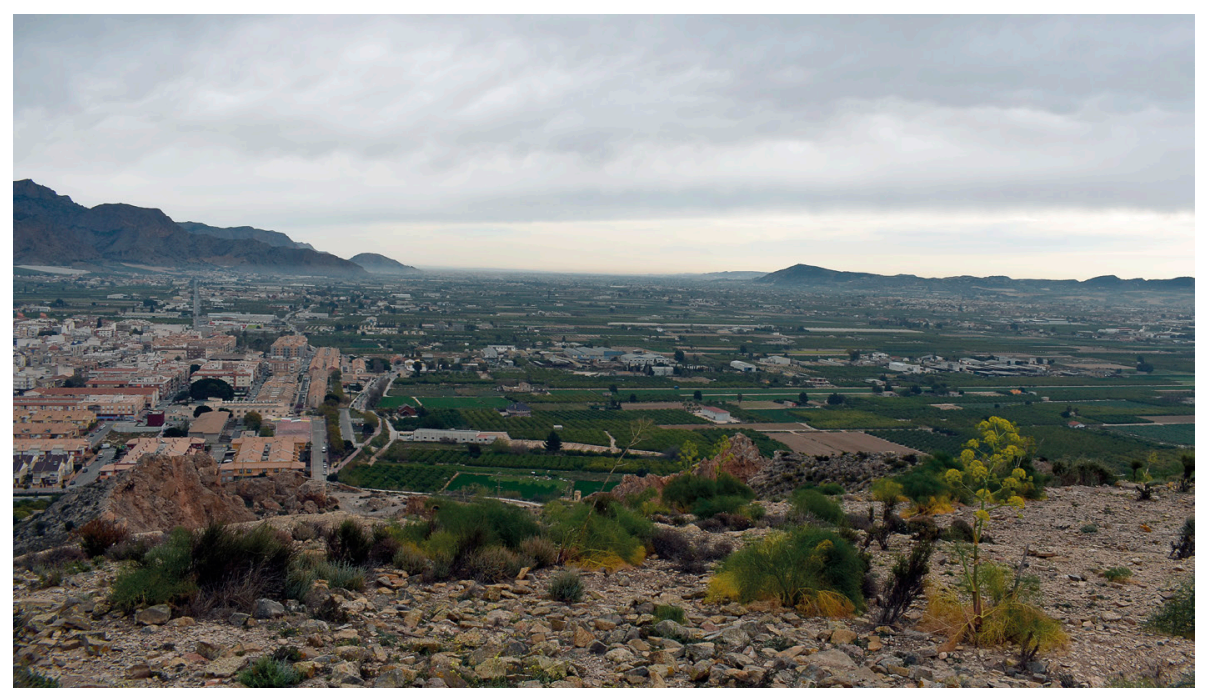

Figura 4. Vista desde el yacimiento de Cobatillas la Vieja de la cuenca baja del río Segura hacia su desembocadura. (Imagen: archivo de los autores)

Figure 4. View of the lower basin of the Segura river towards its mouth from the settlement of Cobatillas la Vieja. (Photography: authors)
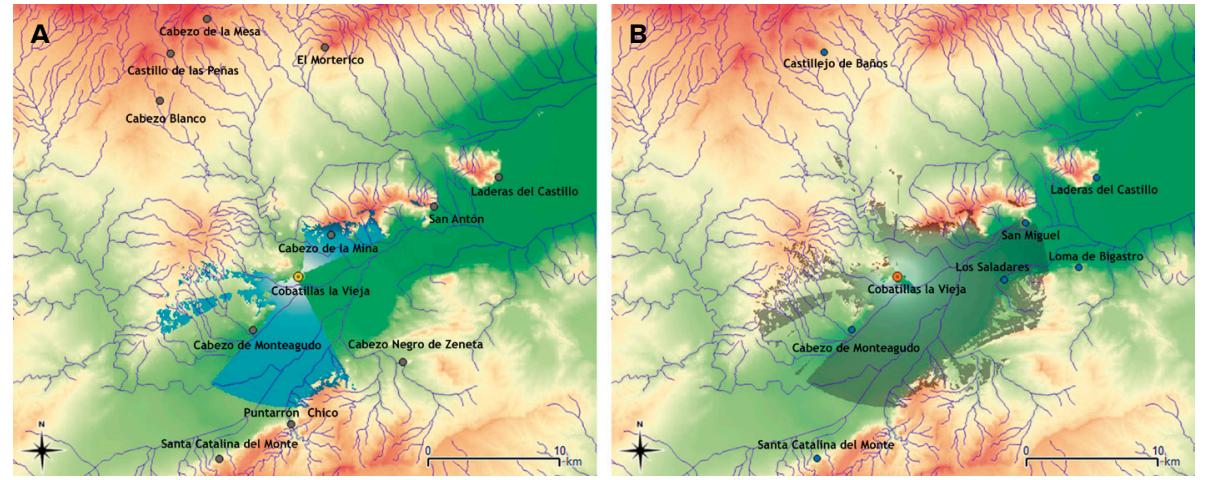

Figura 5. Análisis de visibilidad del complejo arqueológico de Cobatillas la Vieja. A. Cálculo de visibilidad desde el sector argárico respecto a los yacimientos contemporáneos de la zona objeto de estudio. B. Cálculo de visibilidad desde el sector ibérico en el que se encuentra la fase del Bronce Final Inicial y Reciente, y yacimientos contemporáneos de la zona objeto de estudio. (Elaboración propia. MDT: IGN)

Figure 5. Visibility analysis of the settlement of Cobatillas la Vieja: A. Results of visibility analysis from the argaric area and situation of contemporary settlements in the studied area. B. Results of visibility analysis from the Iberian area where the Late Bronze Age site is located, and situation of contemporary LBA settlements. (Design: authors and Digital Terrain Model from Spanish National Geographic Institute)

Io kilómetros y una altura del observador de r,65 metros, es claramente perceptible desde el yacimiento. Por último, el cambio del hábitat desde la Ladera de San Antón hacia San Miguel provoca que esta última ocupación entre no solo dentro del radio de visibilidad de Cobatillas, sino que ocupa una posición más favorable desde la que participar en las rutas de tránsito y comercio en relación a las nuevas sinergias territoriales y estratégicas, una de las probables causas que originó el fenómeno de reestructuración del poblamiento dado tanto en el Bronce Tardío, como en el Bronce
Final del Sureste ibérico. Y todo ello sin contar con los distintos asentamientos secundarios y unidades rurales dependientes que se dedicarían a la explotación de este territorio inmediato de forma intensiva, como el propio Botx-Grupintex (Trelis et alii, 2004) o, para fases posteriores, Los Saladares de Orihuela (Arteaga y Serna, 1979), Casa de Secà (Soriano Boj et alii, 20I2) y la continuidad poblacional del entorno de El Botx ya bajo la posterior órbita política del emergente núcleo de Peña Negra (González Prats, I983; Trelis, 1996; García Borja et alii, 2007; Lorrio et alii, 2020). 
De esta manera, pese al estado de la investigación en el que se encuentra este período cronológico, puede plantearse la existencia de una serie de centros de primera entidad que reproducen patrones similares a los establecidos en época argárica, resultando un ambiente de continuidad locacional en la zona del pasillo del Guadalentín y del tramo bajo del Segura (Ros, 2003). Pese a los diferentes procesos de reordenación y/o reestructuración del poblamiento de época postargárica, parece conformarse la expectativa de una continuidad histórica acorde con la situación de otros escenarios geográficos (Pingel et alii, 2003), marcada por la similitud de las respuestas que tienen lugar entre las distintas comunidades de la región al encontrarse completamente vinculados a partir de relaciones de índole económico, comercial y social. Se reproduciría así un modelo ya planteado para época argárica en la que distintos asentamientos podían realizar actividades complementarias, como ocurría en la zona litoral de Mazarrón con los yacimientos de Ifre, Zapata, Cabezo Negro o Cabezo del Asno (Lull, I983), y que no haría descartables los acuerdos y colaboraciones entre asentamientos, especialmente entre aquellos localizados en un mismo valle o extensión geográfica limitada que pudiera llegar a entenderse como un territorio así mismo compartido (Ros, 2003: 225).

Respecto a Cobatillas, parece que durante el Bronce Final del Sureste ibérico no existe un modelo tan centralizado a nivel político y social como el implantado durante el Argar, afirmación que debe tomarse con prudencia ante la falta de intervenciones sobre asentamientos de la fase inicial del período. Sin embargo, sí que existen esos yacimientos de primera entidad sobre posiciones estratégicas y potencialmente defensivas sobre los que recaería el control político y territorial de sus entornos. Además, se encuentran una serie de evidencias en las que estos centralizan sus actividades, como ocurre con las actividades transformativas del mineral que se daban en el poblado y que no solo requerían de una zona y una serie de artesanos especializados que se encargaran del proceso metalúrgico, sino de una red dedicada al proceso de minería extractiva y comercialización de la materia prima para proveer este taller. Todo ello apunta hacia un modelo en el que, aunque las dependencias políticas no estén claras, existía una importante red comercial entre los núcleos prelitorales y costeros que debió ser estrecha, aprovechando los pasos naturales que conectaban estos diferentes territorios ya fuera por vía terrestre, la más probable en estas fases iniciales, o por vía marítima, como parece desarrollarse durante el denominado como Bronce Final III o inicial en la zona del denominado Sinus Ilicitanus (Blázquez y Ferrer, 20I2; Tent-Manclús y Soria, 20I4) y los primeros contactos foráneos que condicionan una cierta basculación poblacional hacia las zonas costeras, acompañada de la gestación de núcleos autóctonos de gran volumen poblacional e importancia política (Jover et alii, 20I6).

El abandono de Cobatillas la Vieja abriría un segundo período de hiato que se prolongaría hasta el siglo Iv a. C. si no fuera por la noticia del hallazgo en superficie de cerámicas que remiten a los inicios del Hierro Antiguo y a los primeros contactos coloniales iniciados a partir de mediados del siglo viII a. C. (Ros, I985). Por desgracia, estos materiales no han podido ser localizados en los fondos del Museo Arqueológico de Murcia, lo que dificulta cualquier consideración sobre este período de transición del Bronce Final reciente al Hierro Antiguo, período ya de por sí marcado por unas intensas dinámicas de reordenación territorial entre las que Cobatillas podría haber jugado un papel fundamental por sus propias características.

Por último, la etapa ibérica del cerro se encuentra mejor representada ya que en los cuatro cortes practicados - L, M, N y $\tilde{\mathrm{N}}$ - se identificaron tanto datos correspondientes a la urbanística del enclave, como secuencias materiales que retratan las distintas fases de su ocupación. En cuanto a su cronología, se ha propuesto un inicio de la ocupación ibérica a finales del siglo v a. C. (Lillo, I98r: 99), aunque solamente se ha hallado un fragmento de cerámica ática de dicha centuria, pues la mayoría pertenecen a la primera mitad de la siguiente, perdurando el hábitat hasta finales del siglo in a. C. o durante el siglo i a. C., momento de abandono definitivo (García Cano, 1982: 195-196). Sobre el carácter de este asentamiento se ha planteado la existencia de un pequeño fortín avanzado de observación y exploración del 
territorio circundante, dotado de las protecciones naturales del propio cerro, así como de la utilidad de las traseras de las casas como elemento de fortificación (García Cano, 2008: 32). Tales características no hacen más que confirmar la estrecha relación que existe entre Cobatillas la Vieja y su territorio, así como la función que ejerció de manera intermitente como punto de control y centro de producción durante las diferentes etapas de la Prehistoria Reciente del Sureste.

\section{Un núcleo principal de la Vega Baja del Segura: nuevos datos en torno al asentamiento de Cobatillas la Vieja}

\subsection{Estrategias económicas en la continuidad y discontinuidad del hábitat}

Cobatillas la Vieja no puede entenderse sin plantear la relación que existe entre el cerro en el que se erige y el medio que le rodea. Su ubicación en pleno cruce de caminos es el resultado del encuentro entre la principal vía de comunicación del Sureste peninsular, el río Segura, y la rambla Salada, ruta de penetración hacia las primeras estribaciones de la sierra de la Pila, el Altiplano y la Meseta. No obstante, es necesario matizar que los cauces y caudales de estos cursos se han visto atenuados de forma importante por diferentes infraestructuras históricas, modificando una realidad que en época prehistórica fue muy distinta a la actual. En este sentido, se ha estimado que, frente a los $30 \mathrm{hm}^{3}$ que actualmente desagua el río Segura en su desembocadura, sin las retenciones producidas por los embalses esta cifra rondaría los $860 \mathrm{hm}^{3}$ (Morales et alii, 2005: 75), lo que dejaría el valle ocupado por una zona pantanosa cuya máxima extensión coincidiría durante las crecidas del Segura y del río Guadalentín, este último con un caudal especialmente estacional (Calvo, I968). Sin embargo, estas avenidas no deben considerarse como un factor exclusivamente negativo para estas comunidades, sino que tales anegaciones eran la forma natural de enriquecer y fertilizar las tierras de cultivo de la cuenca.

La presencia de estos fenómenos torrenciales se intensificó, además, en los episodios climáticos correspondientes al final de la Prehistoria Reciente. Tras un período de clima más cálido y húmedo que tuvo lugar desde finales del III milenio cal. BC hasta el I 400 cal. BC, se inició una nueva pulsación más fría y seca que coincide con el Bronce Tardío del Sureste y los primeros momentos del Bronce Final (Ros et alii, 2014: 285). Este nuevo período estuvo marcado por una pluviometría caracterizada por lluvias más intensas e irregulares que provocarían una notable incisión sobre terrenos aluviales previamente configurados (Ros et alii, 20I4: 285). La situación cambió hacia el siglo IX a. C., a otra etapa más cálida $\mathrm{y}$ húmeda en la que se registraron eventuales pulsaciones frías hasta llegar al siglo vi a. C. pero donde las lluvias torrenciales permanecen en la zona murciana, continuando con esos arrastres puntuales de sedimentos que seguirían fertilizando las riberas de los ríos hasta su aminoración desde el siglo vi a. C. (Calmel-Avila, 2000: 75-76).

De esta manera se explica la formación de los suelos que conforman la profunda llanura de sedimentos cuaternarios, con residuos aluviales y coluviales de Pleistoceno y Holoceno en torno al Monte de las Brujas y las posibilidades que se abren en torno a su explotación durante el Bronce Final. Además de los litosoles correspondientes a los conos de deyección volcánica triásicos de naturaleza alpujárride, cuyos relieves sobresalen sobre el paisaje -Monteagudo, La Cueva, Cobatillas- (González y Pujante, 2007: 20), los tipos de suelo próximos más abundantes son xerosoles cálcicos y fluvisoles calcári$\cos$ (figura 6). En cuanto a los primeros, es cierto que estos aceptan cultivos, pero para su explotación se debe eliminar su costra caliza endurecida, tarea que implica un coste importante al usar el arado de madera. Pese a que no se descarte su uso, los suelos más favorables son aquellos fluvisoles de la zona inundable del Segura y que, por sus propias características, serían además los que mayor rendimiento permitieran. El problema en cuanto a estos estriba en saber cuánta superficie quedaba por encima de las aguas durante las riadas, y cuánto era practicable para labores agrícolas debido a los almarjales, importantes aún en el siglo xv d. C. y que marcaron las dinámicas productivas especialmente en la margen izquierda del río (Martínez Carrillo, I988; Ros, 2003). 
La zona próxima a Cobatillas por la que discurre la rambla Salada se caracteriza por la existencia de salinas y almarjales que han permanecido hasta la actualidad (Ros, 2003: 235) y cuyo paisaje es el adecuado para la existencia de una intensa vegetación halófila (figuras 6 y 7). Esta condición mengua la extensión cultivada en favor de una actividad ganadera que se beneficia tanto de la presencia de pastos y sal, como de su posición en pleno nudo de comunicaciones entre la cuenca prelitoral y el interior. Tales circunstancias revelan la idoneidad de este paisaje como zona de pasto para el ganado trashumante o trasterminante y fundamenta la presencia de diferentes cañadas históricas en el entorno de Cobatillas la Vieja, como la Cañada Ancha, ahora desfigurada por el paso de las acequias.

De esta manera, el peso de la ganadería para el asentamiento y su entorno tuvo que ser de gran importancia, como revela el estudio osteológico del sector argárico de Cobatillas la Vieja (Mateo y Vázquez, 199I). Los resultados apuntan hacia un peso de la caza testimonial, mientras que son los ovicápridos los que destacan en el registro (62\% de los restos), algo análogo a lo que se identificó en el yacimiento de Puntarrón Chico, cuya ocupación es únicamente argárica (Mateo y Vázquez, I992). Es cierto que hasta la fecha no se disponen de datos del sector del Bronce Final, pero sí que los análisis procedentes de yacimientos cercanos ponen de manifiesto estos mismos patrones para el período, como se ha comprobado en el poblado de Caramoro II (García Borja et alii, 2010: 55-56) o en la fase I de Peña Negra (Aguilar et alii, 1994) con primacía de los ovicápridos y lo limitado de la fauna silvestre.

Otro factor del entorno necesario para sustentar esa cabaña ganadera, y esencial para la conservación de los alimentos, es el recurso de la sal, cuya explotación ha podido ser atestiguada en el interior peninsular (Abarquero et alii, 20IO) y sobre la que se ha planteado su obtención en el Sureste ibérico en zonas como las salinas de La Mata o el propio entorno del Cabezo Redondo de Villena (Mederos, 1999). Su presencia en la rambla Salada no solo se percibe del propio topónimo, sino que se encuentra ampliamente presente en forma de salmuera (Gil et alii, 2010: 616). En cuanto a su forma de explotación, es cierto que apenas se cuenta con información arqueológica para reconstruir su extracción durante esta etapa, pero la existencia de esa salmuera en grandes cantidades en el binterland del yacimiento permitiría fácilmente cocer esta agua saturada de sal en grandes recipientes hasta obtener el recurso buscado (figuras 6 y 7). Así, el papel de Cobatillas respecto a este recurso no solo podría reducirse a su utilidad dentro de las necesidades de la cabaña ganadera, sino también en lo relativo a su explotación y distribución en el marco de los intercambios comerciales de la cuenca baja.

Precisamente gracias a esas relaciones con otros puntos de la región se contextualiza otra de las actividades que se han detectado en las diferentes fases del asentamiento: la metalurgia. Para la época argárica, además del hallazgo de punzones y puñales de cobre y bronce (Medina, I999: I28), se ha planteado la existencia de un taller metalúrgico bajo el taller de sílex a partir del hallazgo de un crisol de piedra volcánica con bronce estannífero (Ayala, 1981: 168-169; Ros, 2003: 24I). La presencia de esta aleación, producto de la mezcla de cobre, estaño y plomo, abre interesantes cuestiones sobre la procedencia de estos minerales en el yacimiento y las posibles rutas que se dieron desde época prehistórica. Por un lado, la llegada del cobre a Cobatillas parece clara desde los filones cercanos identificados en los cabezos de Malnombre o La Mina, así como desde la sierra de Orihuela donde hay presencia de sulfuros y filones de azurita, malaquita, calcopirita, calcosina y cobre nativo (Mojica, 20I3: 85-86). Por otro, más problemática resulta la identificación del posible origen del plomo y la casiterita, mineral del que se obtiene el estaño y que se trata de uno de los menos abundantes del Sureste. La presencia de ambos en las sierras costeras de Cartagena-La Unión y Mazarrón (Ros, I989: 39-40) podría permitir plantear una posible procedencia de estos polígonos mineros, especialmente en el caso del último, donde se ha atestiguado una importante presencia de comunidades del Bronce pleno y reciente relacionadas con la explotación minera (Ros, 1987; Ros, 1989).

En cuanto a la fase del Bronce Final, los datos en este ámbito se centran en el hallazgo de un fragmento de galena y otro de mineral de hierro 


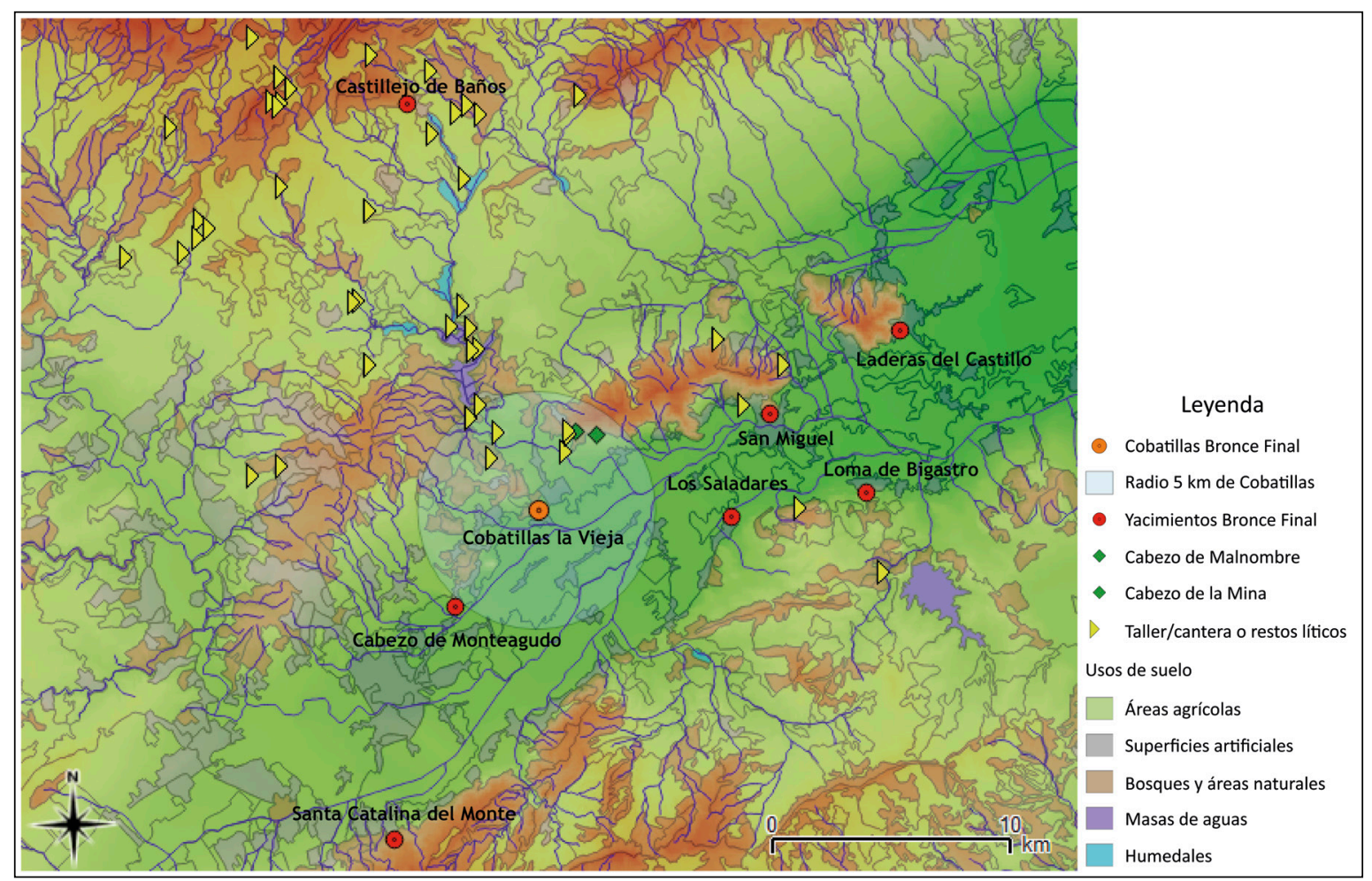

Figura 6. Mapa de los usos de suelo en la zona del yacimiento de Cobatillas la Vieja con los diferentes talleres y canteras de sílex del entorno de la Rambla Salada. (Elaboración propia a partir de la información del SIOSE)

Figure 6. Map of land uses in the hinterland of Cobatillas la Vieja with the different workshops and silex outcrops around Rambla Salada. (Design: authors with the information of Information System on Land Occupation of Spain)

procedentes de la vivienda del corte $\tilde{\mathrm{N}}_{5}$. El primero de ellos, utilizado para la obtención de la plata, cuenta con sus principales yacimientos en la sierra minera Cartagena-La Unión, lo que puede indicar una interesante continuidad en esas rutas de abastecimiento que siguen vinculando el litoral con el yacimiento de Cobatillas la Vieja como ya propusiera Ros (1985: 46). Estas conexiones tendrían lugar aprovechando las vías y pasos naturales, como es el caso de la cuenca prelitoral y la rambla de las Moreras para acceder a las zonas de explotación de Mazarrón, o los diferentes pasos que se abren en la sierra de la Cresta del Gallo y que conectan con la cuenca del mar Menor y la sierra Minera de Cartagena-La Unión. Cómo se produjera esa comunicación es una interesante problemática que, por el momento, queda abierta ante la posibilidad de que esa relación se hiciera directamente por vía terrestre, o bien por vía marítima, introduciéndose en el Bajo Segura desde las posiciones situadas en la propia desembocadura del río. En cuanto al mineral de hierro, sin datos de tipo arqueométrico es sumamente arriesgado proponer áreas de proveniencia sobre este recurso, aunque es necesario apuntar la importancia de los afloramientos de metabasitas y mineralizaciones ferruginosas identificadas en la vertiente norte del Monte de las Brujas y en la ladera sur del inmediato Cabezo Bermejo (Arana y Ortiz, I982), así como al oeste de Santomera y en el Cabezo Bermejo (González y Pujante, 2007: 2I).

De esta manera, la riqueza de recursos del entorno permite plantear tentativamente y a modo de línea de investigación futura, la existencia de una actividad metalúrgica y trabajo de fundición de metales en el poblado o su hinterland, con áreas especializadas de producción y artesanos especializados, como se puede afirmar para la fase argárica de Cobatillas. Concretamente en el identificado como departamento A del asentamiento del Bronce Pleno, se documentó un molde de fundición y un crisol cerámico con una pátina de cobre, estaño y algo de arsénico (Lull, r983: 335; Ayala, 1984: 335), lo que demostraba que la fusión del metal se realizaba en el mismo poblado (Medina, I999: I29). Así, la continuidad de 


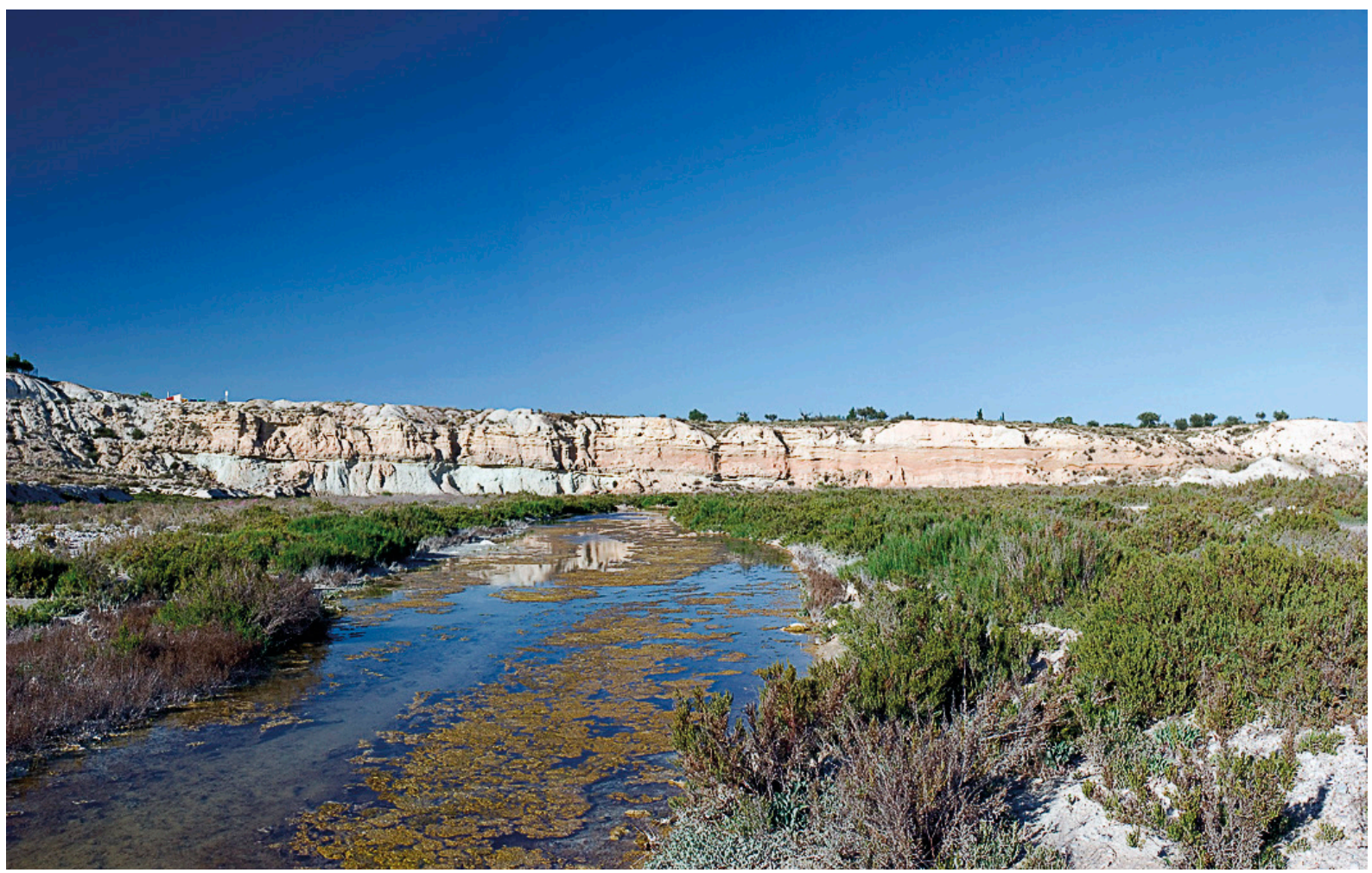

Figura 7. Humedal del Ajauque y Rambla Salada en el término municipal de Santomera. (Imagen: archivo de los autores)

Figure 7. Ajauque and Rambla Salada wetland in the municipality of Santomera. (Photography: authors)

esta actividad puede ser considerada en parte gracias a la potencialidad que los recursos minerometalúrgicos presentan en esta zona del Bajo Segura, y cuyo valor es fundamental para estos primeros siglos del Bronce Final, tanto en lo relativo al comercio de materias primas como de productos elaborados.

\subsection{Competencias espaciales, arquitecturas y materiales en transición}

Las estructuras del Bronce Final inicial localizadas en los cortes identificados como $\mathrm{M}$ y $\tilde{\mathrm{N}}$ corresponden a los niveles más bajos de las secuencias estratigráficas apoyadas directamente sobre la roca base, niveladas al parecer mediante una capa muy compacta de barro y arena de color rojo (Lillo, I976-ı978: 398). El espacio habitacional o vivienda del corte $\tilde{N}$ (figura 8 b y 8c) queda delimitado al lado sur de un muro rectilíneo en el que se halló el pequeño hogar rodeado de piedras y barro del que se obtuvo la muestra de carbón vegetal para el análisis radiocarbónico (Lillo, I976-r978: 398). En cuanto a la morfología y características de la propia estructura, se trata de un paramento del que apenas se conserva un zócalo compuesto por dos hiladas de piedra, toscamente careadas y trabadas en seco, que alcanza los 60 centímetros de ancho (figura 8c). Más complicada resulta la aproximación sobre los niveles identificados por Lillo en el corte $\mathrm{M}$, del que, más allá de apuntar que se corresponde con un estrato de habitación de la Edad del Bronce Final — nivel M.IV—, no aportó más información que la derivada del propio perfil estratigráfico que presenta su excavador (Lillo, I98r: Ior), pero en el que se tuvieron que practicar actividades cotidianas como evidencia el hallazgo de un machacador pétreo que debe estar en conexión con la preparación de los alimentos cuyos restos se identifican con un fondo de cabaña (Lillo, I981: Ior).

Este tipo de patrón arquitectónico apenas presenta diferencias respecto a los modelos de construcción identificados en asentamientos del Bronce Tardío localizados en esta misma región geográfica, como es el caso del Cabezo Redondo de Villena (Hernández et alii, 2or6), Cuesta del Negro (Molina y Pareja, I975), Fuente Álamo (Arteaga y Schubart, I980; Pingel et alii, 2003) o Cerro de la Encina 


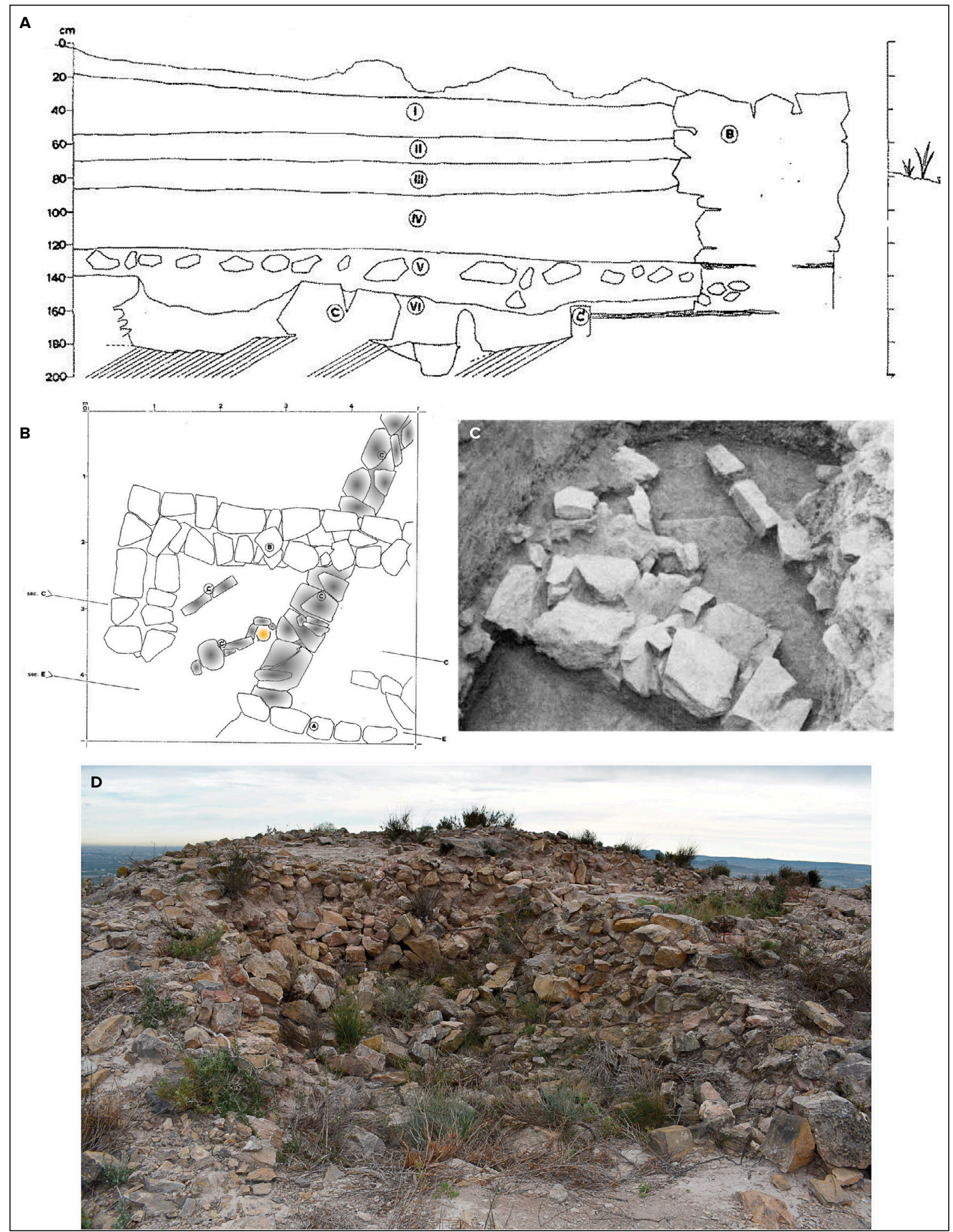

Figura 8. Intervenciones arqueológicas en el sector ibérico de Cobatillas la Vieja. A. Sección estratigráfica central del sector $\mathrm{E}$ del corte Ñ según Lillo (1976-1978: 397). B y C. Planta y fotografía del sector excavado en el corte Ñ en la que se diferencia el muro prehistórico bajo la denominación C (Lillo Carpio 1976-1978: 396 y 399). D. Estado de los cortes M y Ñ del yacimiento en la actualidad. (Imagen: archivo de los autores)

Figure 8. Archaeological excavations in the Iberian sector of Cobatillas la Vieja. A. Stratigraphic profile of Sector $\mathrm{N}$ according to Lillo (1976-1978: 397). B and C. Planimetry and photography of the excavated area in Sector Ñ in which the LBA wall is differentiated as structure C. D. Situation of the $\mathrm{M}$ and $\mathrm{N}$ sectors of the settlement at present. (Photography: authors) 
(Arribas et alii, 1974; Aranda, 200I). No obstante, la perduración de estas formas de construir se ha identificado también durante el Bronce Final inicial del Sureste, tanto por dataciones radiocarbónicas como la procedente de la unidad o espacio habitacional I de E1 Negret (Barciela et alii, 20I2: 127; Jover et alii, 2016: 93), como mediante las adscripciones cronoestratigráficas planteadas en la propia Cobatillas la Vieja (Ros, 1985), en la vivienda de tipo rectangular localizada en la calle Cúspide no 2 en Santa Catalina del Monte (Ruiz, I992: 88) y en la construcción del nivel III de la excavación de la Cuesta de San Cayetano, en Monteagudo (Medina, 2002: 156-157). Si bien la importancia de la piedra es un rasgo característico de los yacimientos del Bajo Segura que se ha atribuido a la importante tradición que en la región tenía este tipo de arquitectura durante la Edad del Bronce (Arteaga y Serna, I979), los conjuntos vasculares asociados a las últimas estructuras y asentamientos citados apuntan a un horizonte claramente diferenciado del período postargárico.

Se abre así una problemática importante en torno a la diferenciación de los patrones arquitectónicos del Bronce Tardío respecto a aquellos del Bronce Final inicial, marcada además por la carestía de datos procedentes de excavaciones sistemáticas correspondientes a estos períodos en el sector central del Sureste ibérico. Entre las viviendas cuadrangulares típicamente postargáricas y las cabañas circulares que se identifican con claridad a partir del Bronce Final pleno, aproximadamente a partir del año rooo a. C. (Jover et alii, 20I6), se dibuja un lapso temporal de gran incertidumbre y escasas evidencias. Sin embargo, los datos obtenidos de los núcleos que se sitúan precisamente en el Bajo Segura, así como en la transición entre este y el río Guadalentín, revelan la continuidad de las estructuras de tipo rectilíneo con plantas angulares y zócalos en piedra; las viviendas de Santa Catalina del Monte y las estructuras de Monteagudo y Cobatillas así parecen apuntarlo. Este patrón de tipo continuista demuestra la importancia que todavía albergan las tradiciones argáricas y postargáricas en la configuración de estas primeras comunidades del Bronce Final, fenómeno que también se repite en lo relativo a las vajillas cerámicas. No obstante, aunque estas manifestaciones se continúen ejecutando, ello no implica que se enmarquen en el nuevo ambiente territorial y político dentro de la reorganización de los sistemas políticos y productivos que se da a partir del final del Bronce Tardío del Sureste.

Volviendo a Cobatillas la Vieja, a pesar de que durante la intervención se identificaran diversos niveles estratigráficos correspondientes a la etapa del Bronce Final (Lillo, I976-I978), el análisis del registro vascular pone de manifiesto que en ambos cortes solamente se encuentra representado un único momento de ocupación. Como ya se ha apuntado, en el corte $\mathrm{N}$ el nivel correspondiente a las estructuras del Bronce Final inicial se correlaciona con el estrato N.VI, mientras que el Ñ.V es el nivel de relleno producto del abandono del hábitat y con presencia de fragmentos de cerámica a mano (Lillo, I976-I978: 399-400). Algo distinta es la secuencia de la estructura del corte $\mathrm{M}$, con dos estratos de habitación que se corresponden con M.IV y M.V con presencia de «tierra quemada y restos de comida» (Lillo, r98r: I05); y el nivel M.III que es el resultado de la preparación del terreno para las construcciones de las fases posteriores, lo que explica la existencia de producciones de este período junto a material rodado ibérico.

En cuanto a la funcionalidad del material cerámico hallado, se trata de un registro material típico de contextos de habitación, con producciones destinadas al servicio de mesa, formas de cocina y contenedores de almacenaje. A pesar de la homogeneidad del conjunto y el tamaño de la muestra, se ha realizado un análisis aproximativo de esta fase mediante el cálculo del número mínimo de individuos y sus características funcionales. En este sentido, el número mínimo de individuos de la vivienda del corte $\tilde{\mathrm{N}}$ -63 en total - se reparte entre un $39 \%$ que alcanzan los vasos abiertos, cuencos y escudillas y un 6r \% en el que se incluyen las orzas cerradas y abiertas destinadas a las funciones de cocina, almacenaje y posiblemente transporte. Mayor precisión se ha podido obtener de los 40 individuos diferenciados de la estructura del corte $\mathrm{M}$, alcanzando un $27 \%$ los tipos asociados al servicio de mesa, un $33 \%$ las ollas y orzas cerradas vinculadas con tareas de cocina y pequeño almacenaje, y un $40 \%$ las orzas y grandes contenedores destinadas al almacenaje y posible transporte. 
Las vajillas cerámicas del Bronce Final inicial, tanto las revisadas en su día por Ros (1985) como las que se encontraban inéditas hasta el momento (figuras 9 y ro), apuntan a un mismo horizonte cultural cuya horquilla cronológica se ha delimitado entre los comienzos del Bronce Final y los inicios del Bronce Final pleno (Ros, 1985: 47). Las características de los conjuntos de los cortes $\mathrm{M}$ y $\mathrm{N}$ presentan una importante homogeneidad tipológica, con una alta uniformidad en sus pastas, la ausencia completa de decoraciones y una serie de rasgos arcaizantes que revelan las reminiscencias de época postargárica que todavía permanecen.

Sin embargo, es cierto que destaca la ausencia de algunas formas propias del último momento del Bronce postargárico, como las cazuelas o los cuencos de carena alta (Ros, I985: 46). Esta carencia podría indicar que, si esta situación se confirmase en nuevos sectores del yacimiento, la ocupación del asentamiento se produjese en una fase algo más tardía que la reflejada por la datación radiocarbónica, no exenta de problemática, pero todavía en el marco del Bronce Final inicial (Castro et alii, I996; Jover et alii, 2016). Hacia esta misma dirección apunta la ausencia en el repertorio cerámico de Cobatillas de tipos procedentes de Cogotas, los cuales reducen su presencia progresivamente en asentamientos de transición como El Tabayà (Belmonte, 2004: 335) o Botx-Grupintex (Trelis et alii, 2004: 322), y que para el Bajo Segura se pone de manifiesto que se trata de una forma en completo desuso, como demuestra su ausencia en los niveles reinterpretados de Santa Catalina del Monte y Monteagudo (Medina, 2002). De esta manera, de nuevo nos encontramos ante unas producciones cerámicas todavía muy ligadas a las etapas anteriores, lo que revela la importancia de una tradición vascular que perdura en el tiempo -y las rutinas de comensalidad y cocina a ellas asociadas-, aunque con determinadas innovaciones e interrupciones que marcan esas tendencias entre el cambio y la continuidad que se dieron entre las comunidades postargáricas y del Bronce Final.

En este contexto se explicaría la mayor presencia de los vasos abiertos de carena baja, una forma que se halla en ambos sectores y que aparece en contextos tanto iniciales como avanzados del Bronce Final pleno. Sin embargo, los ejemplos identificados de este perfil durante la fase inicial son escasos, reduciéndose al ejemplar de la necrópolis de Huéchar 3 y Caldero de Mojácar, mientras que durante la fase plena el paralelo con mayores similitudes se encuentra en el Cerro de la Mora (Lorrio, 2008: 232-233). Las producciones de estos vasos en el corte $\mathrm{M}$ presentan unos bruñidos y acabados de calidad, pero sin llegar al nivel de ejecución y pulido de los dos perfiles documentados en el corte $\tilde{N}$ (figuras 9 y ro). Su alto índice de fragmentación, consecuencia de su escaso grosor, dificulta el conocimiento de esta forma que continuará en contextos de etapas posteriores del Bronce Final hasta bien entrado el I milenio a. C., donde la forma evoluciona hacia los cuencos y tacitas a mano de paredes finas de gran calidad (Ros, 1989: 234-235).

Otros perfiles que comienzan a aparecer son las escudillas con bordes abiertos y labios indicados — tipo 3 de Ros (1985) —, forma evolucionada de los cuencos, pero de mayor diámetro. Esta forma concreta cuenta con paralelos en otros yacimientos de la cuenca del Guadalentín, concretamente en Santa Catalina del Monte y Las Cabezuelas de Totana (Ros, I986: 46) y se encuentra destinada a un servicio de mesa colectivo. En lo relacionado con los contenedores de transporte, destacan las orzas abiertas con borde recto al exterior y de perfil en «S», con paralelos en diversos puntos del eje Guadalentín-Segura, como en El Tabayá (Molina, 1999: I2I-I22), Loma de Bigastro (Soriano Sánchez, I985: I2O-I2I) o Monteagudo (Medina, 2002: 155-156), y la cuenca de Vera. En este último caso destacan los paralelos con el repertorio material de Gatas-VI (Castro et alii, I999: 250), con el que guarda estrechas relaciones especialmente en estas vasijas destinadas al almacenaje, aunque, como ya se ha planteado, no se encuentren las formas con carenas altas y medias que sí se hallaron en el yacimiento almeriense.

Frente a estas formas propias del nuevo período cronológico, continúan existiendo una serie de perfiles que mantienen los tipos y conceptos de época argárica y postargárica, así como con probabilidad las estrategias de producción alfarera, como podría ser el caso de los cuencos abiertos y profundos o las grandes orzas de bordes reentrantes (Ros, 1985: 4I). Uno de los ejemplos más representativos de esta 


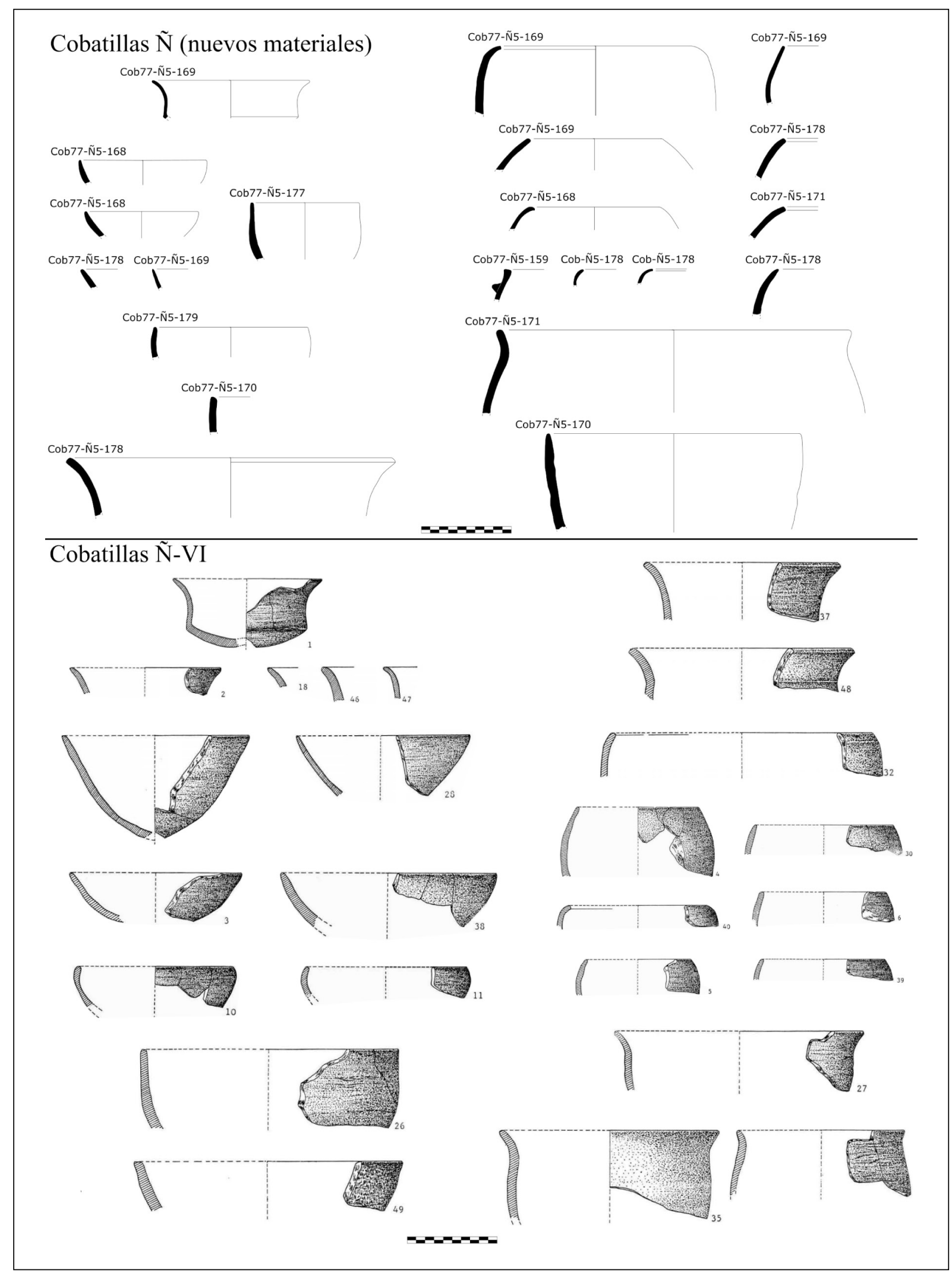

Figura 9. Materiales arqueológicos correspondientes a la fase del Bronce Final Inicial. En la parte inferior se recogen aquellos procedentes del Corte $\tilde{\mathrm{N}}$-VI dibujados por Ros (1985) y en la parte superior las nuevas formas registradas en el proceso de revisión del registro vascular del yacimiento. (Elaboración propia)

Figure 9. Ceramic assemblage from the early Late Bronze Age phase. On top: new materials identified in the review process of the materials from the settlement. On the bottom: types from level N-VI drawn by Ros (1985) 


\section{Cobatillas Corte M}
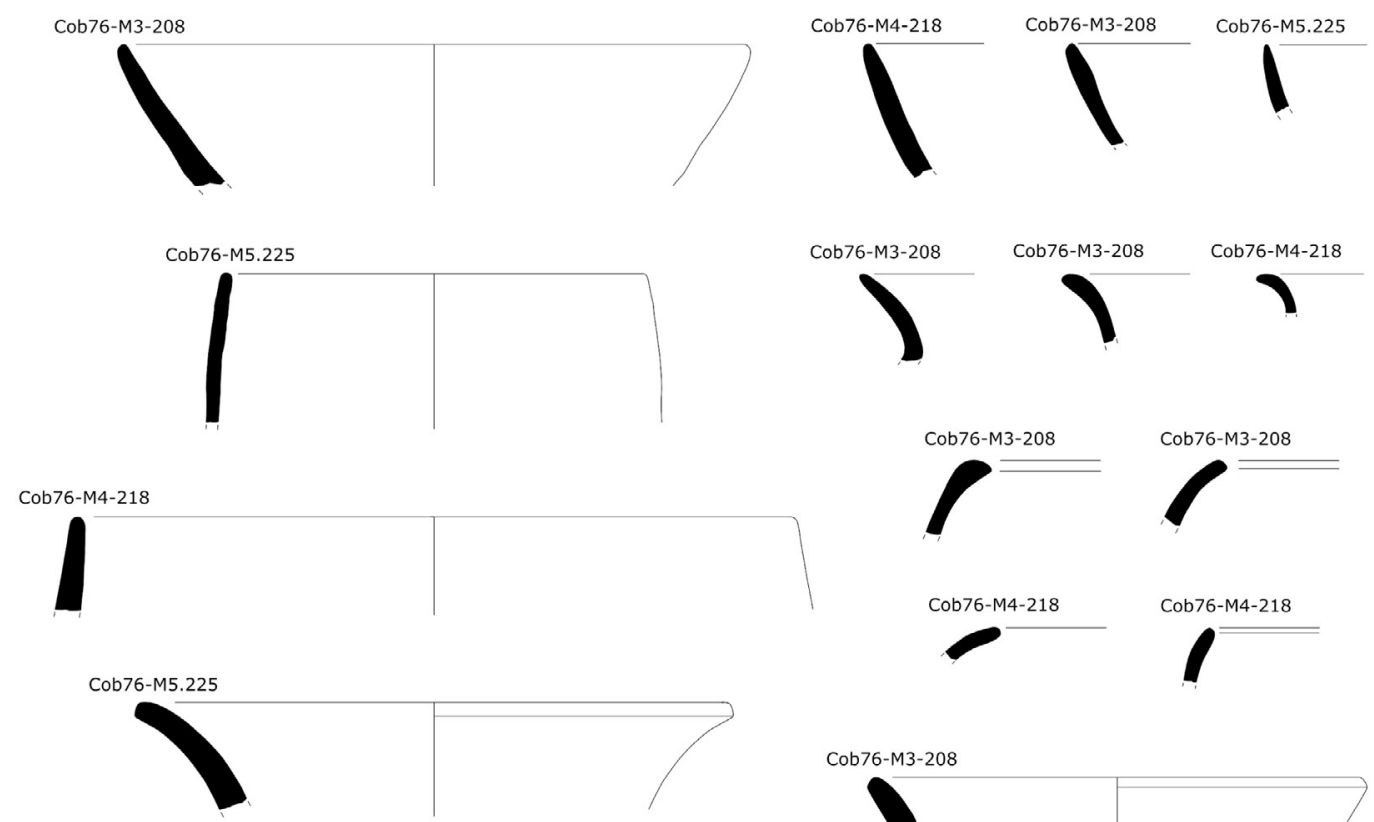

Cob76-M4-218
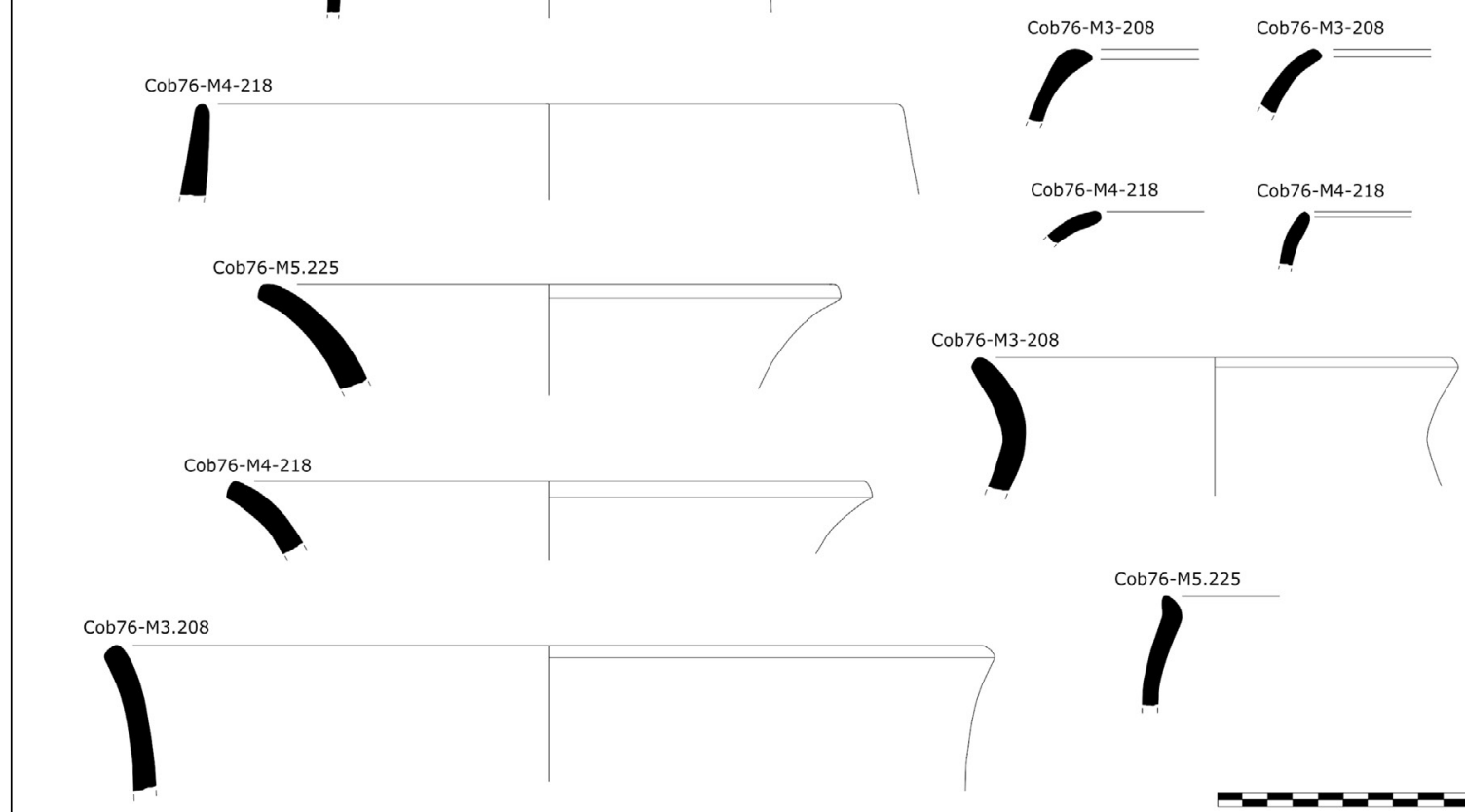

Figura 10. Materiales cerámicos procedentes de los niveles M-III, M-IV y M-V del yacimiento de Cobatillas la Vieja. (Elaboración propia) Figure 10. Ceramic assemblage from M-III, M-IV and M-V stratigraphical levels of Cobatillas la Vieja. (Drawing: authors)

herencia material se encuentra en los cuencos de borde reentrante — tipo $2 \mathrm{~b}$ de Ros (1985) —, cuya forma semiesférica con el borde al interior se encuentra ampliamente documentado en el Bronce Tardío del Sureste ibérico, con ejemplares en la vega baja del Segura (Soriano, 1985: II4, fig. 3.17), la Illeta dels Banyets (Simón, 1997: 80-8I) y el Cabezo Redondo de Villena (Soler, I987: I28). Su aparición residual se ha localizado en otros asentamientos del Bronce Final pleno del Sureste, como en Caramoro II, con solo dos individuos de este tipo identificados (García Borja et alii, 2010: 48), o las Fase III del Peñón de la Reina y de Cerro de la Mora (Lorrio, 2008: 235).

Otras producciones muy presentes en los niveles del Bronce Final inicial y que cristalizan las tradiciones anteriores son las formas cerradas destinadas a la cocina y el tratamiento de los alimentos. Es cierto que su continuidad no puede circunscribirse a este horizonte cultural, pero se trata de tipos característicos bien definidos desde el repertorio vascular argárico (Ros, 1985: 4I) y que perdurarán en su forma y su manufactura hasta mediados del I milenio a. C. (Ros, I989). No obstante, es importante señalar que estos perfiles cerrados no se encuentran en yacimientos cercanos del Bronce Final, como Caramoro II o El Tabayà, y son muy escasas en el Botx (García Borja et alii, 20I2: 39, 42 y 49). Estas diferencias evidencian la existencia de tradiciones distintas de larga duración que se dan entre el eje del Vinalopó y el ámbito del Bajo Segura y que no solo alcanzan a las vajillas cerámicas, sino a todo aquello que rodea las formas de cocinar en términos de dieta, comensalidad y alimentación durante este período. 


\section{Discusión ante los nuevos planteamientos}

Los resultados expuestos en torno al asentamiento de Cobatillas la Vieja y la relación con su entorno, natural y cultural, recuperan este enclave arqueológico como una posición de máximo interés para aproximarnos a las diferentes dinámicas socioeconómicas y territoriales que tienen lugar en esta región del Sureste peninsular a lo largo de sus diferentes períodos de ocupación. Su posición le permite aprovechar los recursos agropecuarios y salinos de su binterland inmediato, así como beneficiarse de un emplazamiento óptimo en pleno nudo de comunicaciones. El encuentro en sus proximidades de las rutas ganaderas y comerciales que transitan por la rambla Salada y el Bajo Segura ha conferido a este entorno un papel activo que se ha mantenido de forma transversal durante períodos posteriores, tal y como demuestra el paso de algunas de las veredas y cañadas históricas más importantes en cuanto a caminos de trashumancia que conectaban esta región con la zona de Cuenca y el interior peninsular (Martínez Carrillo, 20or: 323; Ros, 2003: 234-235). Es en este contexto de actividad asociada a los movimientos ganaderos donde la disponibilidad y explotación de la sal tuvo que jugar un papel fundamental para la comprensión de la idiosincrasia de esta zona desde la Prehistoria.

A ello hay que añadir que el papel estratégico del complejo poblacional no solo se reducía a los tránsitos que se establecieron en dirección este-oeste o hacia el norte, sino que también se han planteado una serie de conexiones que relacionan el asentamiento con las comunidades del litoral murciano, especialmente aquellas ligadas a la explotación de minerales y cuyas evidencias se han relacionado con una actividad metalúrgica desarrollada en el mismo yacimiento. Estas condiciones retratan lo significativo de su creación en tanto supone la búsqueda de una nueva localización en medio de una coyuntura condicionada por profundos procesos de reordenación y reestructuración del poblamiento entre los siglos XIII-XII a. C. (Jover et alii, 20I6). Además, entre las principales ventajas del nuevo emplazamiento en el sector ibérico se encuentra la búsqueda de una mejor posición geoestratégica en términos de control visual y representatividad sobre el entorno inmediato, así como una mayor protección gracias a la propia morfología del cerro, de pendientes abruptas y zonas con escarpes naturales que lo hacen más inaccesible y lo convierten en una posición más fácilmente defendible que el cerro que ocupaba el sector argárico.

No obstante, este clima favorable que se presupone del ambiente comercial y económico del momento no implica la inexistencia de tensiones políticas entre núcleos que compartieran el mismo territorio. Los datos actuales apuntan a que la fase adscrita al Bronce Final inicial de Cobatillas la Vieja se trata de una fundación $e x-n o v o$, con una perduración no demasiado prolongada en el tiempo como revela el estudio de sus estructuras y de sus vajillas cerámicas, con un fuerte componente de homogeneidad y a medio camino entre las nuevas formas y los rasgos arcaizantes del período anterior. El enfoque combinado de los estudios de las producciones cerámicas y la evolución del poblamiento permite comenzar a entrever los cambios y continuidades que se dan en la región como resultado de la evolución en las dinámicas que se producen a nivel territorial y material. Así, aunque en el patrón arquitectónico se haya identificado un modelo constructivo claramente continuista respecto a las etapas del Bronce argárico y postargárico, la evolución de los repertorios de mesa y almacenaje del Bronce Final inicial, con la adaptación de determinadas producciones y especialmente el abandono de otras, implica algunos cambios importantes dentro de un ambiente cultural en plena transición.

La pérdida del papel de las grandes fuentes destinadas a exhibir los alimentos supone el cambio en una práctica social que pasa de contar con un carácter más colectivo a un sentido más restringido, ocupando ese espacio a partir de ahora el cuenco de perfil abierto y uso individual el espacio protagonista (Cutillas, 2020). Puede que estemos ante el reflejo de una sociedad que, en un momento puntual en el que se pretende la reorganización tras la disolución de los modelos político-territoriales postargáricos, el consumo individual en torno a la mesa gane terreno sobre el colectivo, o bien que las nuevas formas de cocinar y presentar los alimentos impliquen el abandono de antiguas costumbres o la readaptación ante la desaparición de la 
llegada de materiales foráneos mediante lazos comerciales interrumpidos, como podría apuntarse con el final de las importaciones de Cogotas.

En definitiva, los nuevos datos aquí presentados sirven para volver a centrar nuestra atención sobre un yacimiento que debe ser recuperado para la investigación. Pero no solo se trata de emprender nuevas excavaciones arqueológicas con el fin de conocer mejor sus distintas fases o precisar con mayor exactitud sus secuencias, sino concebir un proyecto en el que se incluya todo su territorio inmediato con el objetivo de conocer los distintos asentamientos y unidades de producción que constituirían su tejido productivo.

\section{Bibliografía}

Abarquero Moras, F.J. y Guerra Doce, E. (2010): Los yacimientos de Villafáfila (Zamora) en el marco de las explotaciones salineras de la prehistoria europea. Junta de Castilla y León. Valladolid.

Aguilar Baltar, A., Morales Muñiz, A. y Moreno Nuño, R. (1994): "Informe sobre los restos de fauna recuperados en el Corte E (1983-1985) de la Peña Negra (Crevillente, Alicante)". Lucentum, II-I3: 73-9I.

Arana Castillo, R. y Ortiz, R. (1982): "Mineralizaciones de hierro asociadas a metabasitas de Santomera (Murcia)". Boletín de la Sociedad Española de Mineralogía, 5: 135-I47.

Arribas Palau, A., Pareja López, E., Molina González, F., Arteaga Matute, O. y Molina Fajardo, F. (1974): Excavaciones en el poblado de la Edad del Bronce del Cerro de la Encina (Monachil, Granada). El corte estratigráfico $n^{\circ} 3$. Excavaciones Arqueológicas en España, 8r. Ministerio de Cultura. Madrid.

Arteaga Matute, O. y Schubart, H. (1980): "Fuente Álamo. Excavaciones de 1977". Noticiario Arqueológico Hispánico, 9: 245-289.

Arteaga Matute, O. y Serna González, M.R. (1979): "Las primeras fases del poblado de Los Saladares (Orihuela-Alicante). Una contribución al estudio del Bronce Final en la Península Ibérica (Estudio crítico r)". Ampurias: revista de Arqueología, Prehistoria y Etnografía, 4I-42: 65-I37.
Esta orientación sobre proyectos de investigación en los que se promueve el análisis y excavación de territorios sobre la de yacimientos aislados centrados en análisis territoriales (Ros, 2003) será la única estrategia capaz de reportar una realidad global de las diferentes fases de ocupación que no solo se dieron en el Monte de las Brujas, sino que seguro han dejado trazas de poblamiento en sus entornos cercanos. Cobatillas la Vieja se presenta, así, como un escenario fundamental desde el que completar y avanzar en nuestro conocimiento sobre los cambios y continuidades a partir del final de la etapa postargárica y los inicios del Bronce Final del Sureste ibérico.

Ayala Juan, M.M. (198I): "La cultura del Argar en la provincia de Murcia”. Anales de la Universidad de Murcia, 37 (4): I47-I92.

Ayala Juan, M.M. (1982): “El poblamiento argárico”. Historia de la Región de Murcia. Ed. Mediterráneo. Murcia: 55 -Ior.

Ayala Juan, M.M. (2003): "Poblados en llanura y poblados en altura de la Edad del Bronce en Murcia”. En S. Ramallo (ed.): Estudios de arqueología dedicados a la profesora Ana María Muñoz Amilibia. Universidad de Murcia. Murcia: 175-218.

Barciela González, V., Hernández Pérez, M.S., López-Seguí, E.J. y Torregrosa-Giménez, P. (20I2): "A medio camino. Excavaciones arqueológicas en El Negret (Agost, Alicante)”. MARQ, Arqueología y Museos, 5: 103-гзг.

Belmonte Mas, D. (2004): "Un conjunto cerámico del Bronce tardío e inicios del Bronce Final del yacimiento de Tabayà (Aspe, Alicante) Excavaciones arqueológicas de 1987 a 1991. Corte estratigráfico n. II". En L. Hernández y M.S. Hernández (eds.): La Edad del Bronce en tierras valencianas y zonas limitrofes. Instituto de Cultura Juan Gil-Albert, Ayuntamiento de Villena. Villena: 333-345.

Blasco Bosqued, M.C. (1995): "Aproximación a las relaciones entre la Meseta y el Sureste durante la Edad del Bronce". Verdolay, 7: III-II5.

Blázquez, A.M. y Ferrer, C. (20I2): "Role of human actions on landscape changes since the Upper Holocene in the Bajo Segura Basin (SE Spain)". Catena, 97: 3I-40. https://doi.org/Io.IoI6/j.catena.2012.04.010 
Calmel-Avila, M. (2000): "Procesos hídricos holocenos en el bajo Guadalentín (Murcia, SE España)". Cuaternario y Geomorfología, I4 (3-4): 65-78.

Calvo García-Tornell, F. (r968): "La huerta de Murcia y las avenidas del Guadalentín”. Papeles de Geografía, I: III-I39.

Castro Martínez, P.V., Chapman, R.W., Gili i Suriñach, S., Lull Santiago, V., Micó Pérez, R., Rihuete Herrada, C., Risch, R. y Sanahuja Yll, M.E. (1999): Proyecto Gatas 2. La dinámica arqueoecológica de la ocupación prebistórica. Junta de Andalucía. Sevilla.

Castro Martínez, P., Lull Santiago, V. y Micó Perez, R. (1996): Cronología de la Prehistoria Reciente de la Peninsula Ibérica y Baleares (c. 2800-900 cal. $A N E)$. B.A.R. International Series 652. Oxford University Press. Oxford.

Comino Comino, A. (2016): El santuario de la Luz (Santo Angel, Murcia) como elemento de identidad territorial (s. IV/III a.C-I d.C). Tesis doctoral inédita. Universidad de Murcia.

Cutillas Victoria, B. (2020): Producir, consumir, comerciar: territorios y alfarerías del Bronce Final al Hierro Antiguo en el Sureste ibérico. Tesis doctoral inédita. Universidad de Murcia.

García Borja,P.; Carrión Marco, Y., Collado Beneyto, I., Montero Ruiz, I., Muñoz Abril, M., Pérez Jordá, G., Roldán García, C., Roman Monroig, D., Tormo Cuñat, C., Verdasco Cebrián, C. y Vives-Ferrándiz, J. (20I0): "Campaña de excavación arqueológica de urgencia en Caramoro II (Elx, Alacant)". MARQ, Arqueología y Museos, 4: 37-66.

García Borja, P. y De Pedro, M.J. (2013): "El conjunt arqueològic de l'Edat del Bronze de l'Arborcer-Altet de Palau (La Font de la Figuera, València)". En P. García, E. Revert, A. Ribera y V. Biosca (eds.): El naixement d'un poble. Historia $i$ arqueologia de la Font de la Figuera. Ayuntamiento de La Font de la Figuera. La Font de 1a Figuera: 6I-72.

García Borja, P. y Pérez Jordá, G. (20I2): "Ensayo tipológico para el estudio de cerámica prehistórica del País Valenciá. Aplicación a colecciones del Bronce Final". Lucentum, 31: 3I-59. https://dx.doi. org/ıo.I4I98/LVCENTVM20I2.31.03
García Borja, P., Verdasco Cebrián, C., Muñoz Abril, M., Carrión Marco, Y., Pérez Jordá, G., Tormo Cuñat, C. y Trelis Martí, J. (2007): "Materiales arqueológicos del Bronce final aparecidos junto al Barranc del Botx (Crevillent, Alacant)". Recerques del Museu d'Alcoi, 16: 89-II2.

García Cano,J.M. (1982): Cerámicas griegas de la Región de Murcia. Editora Regional. Murcia.

García Cano, J.M. (2008): "Las fortificaciones ibéricas en la Región de Murcia”. Murgetana, II9: 9-36.

Gil Guirado, S., Gil Meseguer, E. y Gómez Espín, J.M. (2010): "El territorio, un bien que conviene ordenar: las salinas del litoral e interior de la Región de Murcia”. Cuadernos Geográficos, 47 (2): 6II-635.

Gil-Mascarell, M. (I98I): "Bronce Tardío y Bronce Final en el País Valenciano”. En M. Gil-Mascarell y C. Aranegui (eds.): El Bronce Final y el comienzo de la Edad del Hierro en el País Valenciano. Laboratorio de Arqueología de Valencia. Valencia: 9-39.

Gil-Mascarell, M. (1985): "El final de la Edad del Bronce. Estado actual de la investigación". Arqueología del País Valenciano: Panorama y perspectivas. Universidad de Alicante. Alicante: I4I-I52.

González Gómez, M.C. y Pujante Martínez, A. (2007): Memoria Prospección Arqueológica Preventiva "SM-GOLF SANTOMERA RESORT". Memoria de intervención inédita. CARM.

González Prats, A. (1979): Excavaciones en el yacimiento protohistórico de la Peña Negra, Crevillente (Alicante): $I^{a} y 2^{a}$ campanas. Ministerio de Cultura. Madrid.

González Prats, A. (1983): Estudio Arqueológico del poblamiento antiguo de la Sierra de Crevillente (Alicante). Anejo I de Lucentum. Universidad de Alicante. Alicante.

González Prats, A. (1990): Nueva Luz sobre la protohistoria del Sudeste. Universidad de Alicante. Alicante.

Hernández Pérez,M.S. (20I2): "El Cabezo Redondo (Villena, Alicante) y el Bronce Tardío en las tierras meridionales valencianas". En J.A. Rodríguez y J. Fernández (eds.): Cogotas I. Una cultura de la Edad del Bronce en la Peninsula Ibérica. Universidad de Valladolid. Valladolid: III-I46. 
Hernández Pérez, M.S., García Atienzar, G. y Barciela González, V. (2016): Cabezo Redondo (Villena, Alicante). Universidad de Alicante. Alicante.

Hernando Gonzalo, H. (2002): Arqueología de la identidad. Akal. Madrid.

Jiménez Lorente, S., Ayala Juan, M.M. y Navarro Hervás, F. (2005): "Primera campaña de prospecciones en Rambla Salada (Santomera, Murcia)". Memorias de Arqueología, I3: 27-46.

Jiménez Lorente, S., Ayala Juan, M.M. y Navarro Hervás, F. (2006): "Rambla Salada (Santomera, Murcia). Segunda campaña de prospecciones arqueológicas". Memorias de Arqueología, I4: 599-606.

Jover Maestre, F.J., Lorrio Alvarado, A.y Díaz Tena, M.A. (20r6): "El Bronce Final en el Levante de la Península Ibérica: bases arqueológicas y periodización”. Complutum, 27 (I): 8I-I08. http:// dx.doi.org/ro.5209/CMPL.53218

Lillo Carpio, P.A. (1976-1978): "Corte estratigráfico en el poblado ibérico de Cobatillas la Vieja”. Empuiries: revista de món clàssic i antiguitat tardana, 38-40: 395-400.

Lillo Carpio, P.A. (1981): El Poblamiento ibérico en Murcia. Universidad de Murcia. Murcia.

Lorrio Alvarado, A. (2008): Qurénima. El Bronce Final del Sureste de la Peninsula Ibérica. Real Academia de la Historia-Universidad de Alicante. Madrid.

Lorrio Alvarado, A. (2009-2010): "El Bronce Final en el Sureste de la Península Ibérica: una (re)visión desde la arqueología funeraria”. Anales de Prehistoria y Arqueología, 25-26: II9- I76.

Lorrio Alvarado, A., Pernas García, S., Torres Ortiz, M., Trelis Martí, J., Camacho Rodríguez, P. y Castillo Vizcaino, L. (2020): "Peña Negra (Crevillent, Alicante): la ciudad orientalizante de Herna y su territorio". En S. Celestino y E. Rodríguez (eds.): Un viaje entre el Oriente y el Occidente del Mediterráneo. Ed. Mytra. Mérida: 52I-540.

Lull Santiago, V. (1983): La cultura de El Argar (un modelo para el estudio de las formaciones económico-sociales prehistóricas). Akal. Madrid.

Martínez Carrillo, M.L. (1988): “Dehesas y pastos comunes en los finales del siglo XV". Murgetana, 76: III-I2I.
Martínez Carrillo, (200I): "Caminos de trashumancia hacia los extremos sudorientales en la Baja Edad Media". XXVII Semana de Estudios Medievales. Estella, I7 a 21 de julio de 200o. Itinerarios medievales e identidad hispánica (Separata). Pamplona: 293-328.

Martínez Rodríguez, A. y Ponce García, J. (2002): "Excavación arqueológica de urgencia en el subsuelo de la antigua Iglesia del Convento de las Madres Mercedarias (C/ Zapatería - C/ Cava, Lorca)". Memorias de Arqueología, Io: 89-137.

Martínez Monleón, S. (2015): "Consideraciones en torno al poblamiento durante el Bronce Tardío en las comarcas del Bajo Segura y Bajo Vinalopó (Alicante)". MARQ. Arqueología y Museos, 6: 65-79.

Mateo Saura, M.A. y Vázquez Antón, J.M. (1991): "Los restos óseos de fauna del poblado argárico de Cobatillas la Vieja (Murcia)". Verdolay, 3: 33-37.

Mateo Saura, M.A. y Vázquez Antón, J.M. (1992). "Los restos óseos de fauna del yacimiento argárico del Puntarrón Chico, Beniaján (Murcia).” Trabajos de Prehistoria, 49: 357-364. https://doi. org/Io.3989/tp.1992.v49.io.55I

Mederos Martín, Alfredo (1999): "La metamorfosis de Villena. Comercio de oro, estaño y sal durante el Bronce Final I entre el Atlántico y el Mediterráneo (I625-1300 AC)". Trabajos de Prehistoria, 56 (2): II5-I36. https://doi.org/Io.3989/ tp.1999.v56.i2.278

Medina Ruiz, A.J. (1999): "Estado de conservación del sector argárico de Cobatillas la Vieja, Santomera-Murcia”. Memorias de Arqueología, 9: I25-I54.

Medina Ruiz, A.J. (2002): "Excavaciones en la Cuesta de San Cayetano (Monteagudo, Murcia)". Memorias de Arqueología, II: 135-164.

Medina Ruiz, A.J. (2010): "Excavación arqueológica de un ámbito urbano de época romana, la Plaza de la Iglesia de Monteagudo (Murcia)”. Memorias de Arqueología, 15: 19I-216.

Mojica García,L. (2013): Elyacimiento ibérico de la Ladera de San Antón (Oribuela, Alicante): revisión y propuestas de estudio. Fundación José María Soler. Villena.

Molina González, F. (1978): "Definición y sistematización del Bronce Tardío y Final en el Sureste de la Península Ibérica". Cuadernos de Prehistoria de la Universidad de Granada, 3: 159-233. 
Molina González, F. y Pareja, E. (1975): Excavaciones en la Cuesta del Negro (Purullena, Granada). Campaña de 197r. Excavaciones Arqueológicas en España, 86. Ministerio de Cultura. Madrid.

Molina Mas, F. (1999): "La cerámica del Bronce Tardío e inicios del Bronce Final en el valle medio del río Vinalopó: el ejemplo del Tabayá (Aspe, Alicante)". Revista d'Arqueologia de Ponent, 9: II7-I30.

Morales Gil, A., Rico Amorós, A. M. y Hernández Hernández, M. (2005): “El trasvase Tajo-Segura”. Observatorio Medioambiental, 8: 73-IIо.

Pingel, V., Schubart, H., Arteaga Matute, O., Roos, A.M.y Kunst, M. (2003): "Excavaciones arqueológicas en la ladera sur de Fuente Álamo: campaña de 1999". SPAL, I2: 179-229. http://dx.doi. org/ro.12795/spal.2003.iiz.08

Ros Sala, M.M. (1985): "El período del Bronce Final en el conjunto arqueológico de Cobatillas la Vieja (Murcia)". Anales de Prehistoria y Arqueologia, I: 33-47.

Ros Sala, M.M. (1986): "Datos para el estudio del Bronce Tardío y Final en el valle del Guadalentín: el poblado de Las Cabezuelas (Totana, Murcia)". Anales de Prebistoria y Arqueologia, 2: 39-47.

Ros Sala, M.M. (1986-1987): “El poblado de Santa Catalina del Monte: Una aproximación a la urbanística del s. vi a.C. en el ámbito territorial del eje Segura-Guadalentín”. CuPAUAM: Cuadernos de Prehistoria y Arqueología, I3-I4: 77-88. http:// dx.doi.org/Io.15366/cupauami987.I4.007

Ros Sala, M.M. (1989): Dinámica urbanistica y cultura material del Hierro Antiguo en el Valle del Guadalentin. Colegio Oficial de Arquitectos de Murcia. Universidad de Murcia. Murcia.

Ros Sala, M.M. (2003): "Panorama actual y perspectivas de investigación en torno a las comunidades del Bronce Tardío en el Valle del Guadalentín (Murcia)". En S. Ramallo (ed.): Estudios de arqueología dedicados a la profesora Ana María Muñoz Amilibia. Universidad de Murcia. Murcia: 219-247.

Ros Sala,M.M., Navarro Hervás, F.y Rodríguez Estrella, T. (20I4): "Génesis y evolución de un paisaje semiárido mediterráneo: el caso del entorno de Punta de los Gavilanes. Puerto de Mazarrón (Murcia)". Uso y gestión de recursos naturales en medios semiáridos del ámbito mediterráneo: II Encuentros Internacionales del Mediterráneo. PHICARLA.Universidad Popular de Mazarrón. Mazarrón: 273-290.
Ruiz Sanz, M.J. (1998): “Excavaciones de urgencia en el poblado de Santa Catalina del Monte (Verdolay, Murcia)", Memorias de Arqueologia, 7 : 77-II6.

Simón García, J.L. (1997): "La Illeta: asentamiento litoral en el Mediterráneo occidental de la Edad del Bronce". En M. Olcina (coord.): La Illeta dels Banyets (El Campello, Alicante). Estudios de la Edad del Bronce y Época Ibérica. Museo Arqueológico de Alicante. Alicante: 47-I32.

Soler García, J.M. (1987): Excavaciones arqueológicas en el Cabezo Redondo (Villena, Alicante). Diputación Provincial de Alicante, Instituto Alicantino de Cultura Juan Gil-Albert. Alicante.

Soriano Boj, S., Jover Maestre, F. J. y López Seguí, E. (20I2). "Sobre la fase orientalizante en las tierras meridionales valencianas: el yacimiento de Casa de Secà (Elche,Alicante) y la dinámica del poblamiento en el «Sinus Ilicitanus»". Sagrntvm, 44: 77-97. https://doi.org/ıo.7203/SAGVNTVM.44.I772

Soriano Sánchez, R. (1984): "La Cultura del Argar en la Vega Baja del Segura”. Sagvntum, I8: I03-I45.

Soriano Sánchez, R. (1985): "Contribución al estudio del bronce tardío y final en la Vega Baja del Segura”. Sagvntvm, I9: 107-I29.

Tent-Manclús,J.E. y Soria,J.M. (20I4): "Formación y desecación del sinus ilicitanus (sur de Alicante) en los últimos I50oo años". Geogaceta, 55: 35-38.

Trelis Martí,J. (1996): “Aportaciones al conocimiento de la metalurgia del Bronce Final en el sureste peninsular: el conjunto de moldes de E1 Bosch (Crevillente-Alicante)". XXIII Congreso Nacional de Arqueología. Ayuntamiento de Elche. Elche: 185-I90.

Trelis Martí, J., Molina Mas, F. A., Esquembre Bebia, M.A. y Ortega Pérez, J. R. (2004): “E1 Bronce Tardío e inicios del Bronce Final en el Botx (Crevillent, Alicante): Nuevos hallazgos procedentes de excavaciones de salvamento". En L. Hernández y M.S. Hernández (eds.): La Edad del Bronce en tierras valencianas y zonas limítrofes. Instituto de Cultura Juan Gil-Albert, Ayuntamiento de Villena. Villena: 319-324. 